\title{
Numerical modelling of hot polymer-coated steel pipeline joints in
}

\author{
bending \\ Finian McCann ${ }^{1}$, Guido Ridolfi ${ }^{2}$, Erwan Karjadi ${ }^{2}$, Harm Demmink ${ }^{2}$, Helen Boyd ${ }^{2}$ \\ ${ }^{1}$ School of the Built Environment and Architecture, London South Bank University, UK. \\ ${ }^{2}$ Heerema Marine Contractors, Leiden, Netherlands.
}

Abstract: A numerical method to analyse the effect of the application of polymer coatings on the bending resistance of steel pipeline joints is presented. Experiments were conducted to investigate the influence of the thickness of polymer field joint coatings and the cooldown time provided after applying the coatings on the behaviour of pipeline joints when being bent during reeling operations. Temperature readings were obtained from thermocouples inside the polymer field joint coating during the application process, and pipeline ovality measurements were taken during mechanical testing. Thermal modelling of the coating application procedure was developed using COMSOL Multiphysics modelling software; this model is validated against the thermocouple readings, while a mechanical model simulating the pipe being bent to a reel developed in Abaqus finite element modelling software is described. The temperature outputs, areas of stress concentration and pipe ovalities obtained from the experiments are shown to be predicted accurately by the numerical models. After successful validation of the numerical models, a parametric study assessing the influence of field joint coating 
thickness and cooldown times is described, whose results are used to find an optimal solution to reduce the cooldown time required prior to bending the pipe without buckling.

Keywords: nonlinear mechanics; polymers; reel-lay method; subsea engineering thermo-mechanical modelling 


\section{Introduction}

In the field of subsea engineering, the reel-lay method of offers numerous logistical and technical advantages over alternative pipe laying methods such as J-lay as Slay $[1,2]$. Compared to these onboard fabrication methods, onshore fabrication procedures are far less susceptible to the suspension of operations due to adverse weather conditions, and the overall process of unreeling and laying the pipe is considerably quicker and thus also less likely to be affected by scheduling or weather delays [2].

In order to maintain the temperature of production fluids during operation and shutdown conditions, thicker coatings must be employed to enhance the thermal performance of the pipelines [3]. There are considerable challenges inherent to installing pipes with such thick coatings; previous finite element modelling [4,5] has found that combinations of coating thickness, pipe wall thickness and mismatch in material properties across a field joint can result in unacceptable buckling. These challenges are especially present when employing the reel-lay method where the pipeline, welds and coatings typically undergo a number of bending events during fabrication, spooling, unspooling and eventual touchdown on the seabed; these events lead to noticeable plastic deformation of the steel pipe. Previous projects [3] have seen 12.75 " outer diameter (OD) pipelines with a 53 mm-thick multiple layer polypropylene (MLPP) coating successfully reeled and laid; the impetus for the investigation described in the current work is to ascertain 
whether this capacity can be extended to considerably thicker coating systems, such as 7LPP or 9LPP up to $120 \mathrm{~mm}$ thick. Extending the envelope to encompass these coating solutions would allow the reel-lay method to be used in ever more challenging environments and greater water depths. The current work focusses on API [6] grade X65 steel pipelines with a 9LPP coating with an overall thickness of $100 \mathrm{~mm}$.

The reel-lay method entails initially fabricating the pipeline onshore in $500 \mathrm{~m}$-long stalks, which are themselves formed from individual factory-coated $12.2 \mathrm{~m}$ long joints welded together end-to-end. In order not to damage the polymer coating during the welding procedure, the coating is typically cut back approximately 300 mm either side of the weld with a $30^{\circ}$ chamfer (see Figure 1) in order to provide a smooth transition between the linepipe coating and the field joint coating (FJC) and to avoid stress raisers due to sudden geometric and material discontinuities [5]. The geometry of the chamfer is designed in accordance with DNV-RP-F102 [7] and DNV-RP-F106 [8] pipeline standards.

After the weld has been performed and passed inspection, an injection-moulded polypropylene (IMPP) FJC is applied around the weld in order to replace the coating material that had been cut back prior to welding. The IMPP application process (described in more detail in Section 2.2) involves heating the steel to around $240^{\circ} \mathrm{C}$. Since steel loses strength and stiffness with increasing temperature, as observed by $[9,10]$ and in particular by [11-14] for high strength steels similar 
to grade X65 considered in the current work, the field joint is left to cool down so that the steel pipe can regain its strength and be bent to the reel without buckling or deforming excessively. The reduction in strength of a typical high strength steel with increasing temperature is shown in Figure 2.

It is thus necessary to determine how long is required for the field joint to cool down sufficiently so that reeling can take place safely. For field joints within a single stalk this is not an issue since the stalks are fabricated well in advance of reeling and so the field joints will have cooled back down to ambient temperature and regained full strength. During reeling operations, successive stalks are required to be joined together while reeling has been paused, with the pipeline subject to barge motions and the associated fatigue effects which can weaken the welds. It is thus advantageous that reeling is paused for as short a time as possible, so that allowances made for fatigue effects need not be too onerous; current best practice is to pause reeling at least overnight. One of the primary factors dictating the cooldown time is the thickness of the insulating IMPP field joint coating, which can be controlled by using a specially-shaped mould for the IMPP, creating either hourglass or full FJCs (see Figure 3). A thinner coating allows for a quicker cooldown time and hence the steel strength is regained sooner. However, previous experience [3-5] has shown that thicker FJCs contribute noticeably to the overall bending resistance of the field joint, even though the elastic stiffness and strength of steel are orders of magnitude greater than those of the polymer coatings. This is 
because while the steel yields at a strain of around $0.2 \%$ and loses much of its stiffness thereafter, the polymers maintain their elastic stiffness up to strains of approximately $2 \%$, and thus contribute to the stability of the steel pipe when it is deforming plastically and help to prevent buckling. An optimal FJC thickness can be found where a balance is struck between steel strength being regained sooner and the contribution of the polymer material to bending strength.

In the current work, the experimental campaign is described and some results presented, followed by a description of the thermal and mechanical numerical models developed to simulate the behaviour of the hot tie-in field joints. Upon successful validation of the models against the experimental results, a parametric study varying the thickness of the FJC and the cooldown time prior to bending is described from which an optimum field joint coating can be obtained.

\section{Experimental investigation}

The behaviour of a pipeline with $100 \mathrm{~mm}$-thick nine-layer polypropylene (9LPP) coating was investigated in order to extend reeling capability beyond coatings 53 $\mathrm{mm}$ in thickness. Given that the inner radius of the reel employed onboard Heerema Marine Contractor's deepwater construction vessel DCV Aegir is $8 \mathrm{~m}$, the outer diameter of bare or thinly-coated reel-laid pipes is typically limited to 16 " so that strains in the innermost layer of pipe around the reel are limited to $2.5 \%$ in accordance with DNV guidance [15]. For thicker coatings, the strains in the outer surface of the coating increase accordingly, with a greater risk of damage to the 
pipe walls and coating. Thus, the primary aim of the experimental investigation was to assess whether these higher levels of strain could be withstood satisfactorily by the steel pipe and coating materials.

\subsection{Specimens}

Factory-coated test specimens were prepared comprising three pipe segments of grade X65 steel, joined by $20 \mathrm{~mm}$ girth-welded field joints. The field joints were $3.45 \mathrm{~m}$ apart in order to test two FJCs at the same time on the rig. The outer diameter of the pipes was nominally $327 \mathrm{~mm}$, while the wall thickness was 15.7 $\mathrm{mm}$, giving a diameter-to-thickness ratio of 20.1 ; the pipes were intentionally chosen to be this slender in order to provide a more onerous combination of pipe wall thickness and coating thickness $[4,5]$. The composition of the 9LPP coating is shown in Figure 4; after a thin three-layer polypropylene (3LPP) base layer is applied, alternating layers of foam and solid polypropylene are provided in order to combine the enhanced thermal insulation of the foam with the relative stiffness and strength of the solid polypropylene layers. Material characterisation was undertaken in parallel with the experimental investigation in order to determine the thermal and mechanical properties of the various materials used in the pipeline system [16].

While the majority of specimens prepared were intended for full mechanical bend testing, a number of specimens were reserved in order to measure the heat evolution occurring within the liquid IMPP after injection. The temperatures were 
recorded using thermocouples, which were arranged as shown in Figure 5, in order to calibrate and validate thermal numerical models.

Three different FJC geometries were investigated: full, with a nominal thickness of $108 \mathrm{~mm}$ to include a $50 \mathrm{~mm}$ long, $8 \mathrm{~mm}$ thick overlap at the top of the chamfer (see Figure 4), a thick hourglass with a nominal thickness of $50 \mathrm{~mm}$, and a thin hourglass with a nominal thickness of $40 \mathrm{~mm}$. A bare pipe with no FJCs was also tested in the bend rig as a control specimen. Temperature readings recorded by the thermocouples are presented and discussed in Section 3.2.3.

\subsection{Setup and procedure}

The tests were conducted at Heriot Watt University, Edinburgh. A coating station similar to those used at project production facilities was installed onsite; for the specimens being used solely for temperature development measurement, the thermocouples were also installed in the coating station. The ambient temperature was recorded prior to each test.

The process of applying the IMPP coating involves heating the bare steel substrate to temperatures around $240^{\circ} \mathrm{C}$ with an induction heater (see Figure 6), then applying a thin layer of fusion bonded epoxy (FBE) followed by thin layers of chemically-modified polypropylene (CMPP) to encourage bonding between the steel substrate and the IMPP. The chamfers of the linepipe coating are reheated to encourage bonding with the IMPP, and a mould is then fitted around the field joint. 
The liquid polypropylene is then injected at $200^{\circ} \mathrm{C}$ into the mould, which is removed after some solidification of the polypropylene.

The bending rig consisted of a reel former with a radius of curvature equal to $8 \mathrm{~m}$, and a straightening former with a radius of curvature equal to $55.84 \mathrm{~m}$ (see Figure 7); these radii are representative of those of the reel drum and straightener employed onboard DCV Aegir. After coating of the field joints was completed in the coating station, the pipe specimen was installed into the bending rig. One end of the pipe was anchored with a pin, while the other end of the pipe was attached to a pull head, which was translated between the two formers by means of a cable attached to a crane.

After a pre-defined cooldown period (typically between one to three hours), the test procedure was initiated, whereby the specimen underwent five full bending cycles, with each cycle consisting of a number of steps: i) the pipe is bent to the reel former and held; ii) the pipe is released, iii) the pipe is bent to the straightening former and iv) the pipe is finally released again. The pipe was held to the reel former overnight in order to simulate the effect of the IMPP cooling down on the reel prior to resumption of reeling operations. During qualification testing, pipeline samples are subjected to five full cycles in order to ensure that pipe integrity is maintained during initial spooling, straightening and pipelay, along with contingencies for weather delays or the possibility of requiring to recover the pipe back onto the reel and then to unspool again. Ovality measurements were taken at 
salient locations after each cycle step, where the ovality is defined according to DNV design guidance [15] as:

$$
\text { ovality }=\left(D_{\max }-D_{\min }\right) /\left(D_{\text {nom }}\right)
$$

where $D_{\max }$ is the maximum diameter of the deformed pipe, $D_{\min }$ is the minimum diameter of the deformed pipe and $D_{\text {nom }}$ is the original nominal diameter of the pipe. The ovality measurements were taken using optical metrology equipment inserted inside the pipe; thus, the values used in Eq.(1) relate to the inner diameter of the steel pipes with $D_{\text {nom }}=295.7 \mathrm{~mm}$.

\section{Numerical modelling}

Finite element modelling was used during the planning phase of the campaign in order to select suitable specimens, coating thicknesses and cooldown times for the tests; these models were refined further and validated against the experimental results.

\subsection{Modelling approach}

In order to model the behaviour of the hot tie-in field joints, a thermo-mechanical model was required. Since fully coupled thermo-mechanical numerical analysis can be considerably computationally expensive, an alternative approach was employed in the current work whereby the analysis is separated into a thermal model to simulate the process of applying the IMPP, followed by a mechanical model 
simulating the process of bending the pipe that incorporates the temperature field predicted by the thermal model along with temperature-dependent material models. Thermal modelling was performed using COMSOL Multiphysics [17], with the temperature fields around the field joint exported at a number of defined cooldown intervals. These fields were then mapped onto an Abaqus mechanical model that simulated bend testing of the pipe. Given that the cooldown times are in the order of hours and that the bending events were performed in a number of minutes, there is a difference in orders of magnitude between the cooldown rates and the strain rate during the bend tests. Thus, it is reasonable to assume that heat flow within the field joints during bending was negligible and so can be accurately modelled by assuming a static temperature field in the mechanical models, thus achieving a considerable degree of efficiency over a fully coupled thermo-mechanical model.

\subsection{Thermal modelling}

A section of the pipe around a particular field joint was represented by twodimensional models assuming axisymmetric conditions about the longitudinal axis, with symmetry also assumed at the weld plane. The composition of the models relating to the three different FJC geometries are shown in Figure 8. It was found from sensitivity analysis that the change in temperature was negligible at a distance of $2 \mathrm{~m}$ from the weld, and thus the models were extended to include this portion of the pipe specimens. Triangular elements were used to mesh the model, with 
nominal seeds at $5 \mathrm{~mm}$; the meshing algorithm increased the mesh density in areas with acute changes in geometry such as at the chamfer toes.

Temperature-dependent thermal conductivities and heat capacities obtained from material characterisation of coating materials and steel pipe materials were applied in the numerical models; typical values of these properties $[16,18]$ across the range of temperatures considered in the current analysis are summarized in Table 1.

\subsubsection{Boundary conditions}

An air cooling boundary heat flux was imposed on external surfaces, with the convection transfer coefficient set equal to $10 \mathrm{~W} / \mathrm{m}^{2} / \mathrm{K}$ [19]. When validating the numerical model against the experimental data, the ambient temperature was set equal to that recorded onsite on the day of testing; for the subsequent parametric study, the ambient temperature was set equal to $20^{\circ} \mathrm{C}$.

Initially, it was assumed that internal airflow was negligible and so no boundary heat flux was defined along internal surfaces; this assumption is accurate for considerably long lengths of pipe where there is little possibility for air to flow. However, for the shorter test specimens the effects of internal air cooling on the temperature within the field joint coating are significant since heat is drawn from the polymer coating by the relatively highly-conductive steel pipe, which is being continually maintained at a lower temperature by the air. A sensitivity analysis was performed whereby the internal temperature and heat transfer coefficient were varied between $15-21^{\circ} \mathrm{C}$ and $1-10 \mathrm{~W} / \mathrm{m}^{2} / \mathrm{K}$, respectively. It was found that 
applying a temperature of $18^{\circ} \mathrm{C}$ and a heat transfer coefficient of $3 \mathrm{~W} / \mathrm{m}^{2} / \mathrm{K}$ on the internal surfaces of the models provided appropriate internal cooldown rates.

\subsubsection{Analysis steps}

The analysis was divided into a number of steps representing the IMPP application procedure as conducted onsite. Firstly, induction heating of the steel was modelled using a body heat flux defined appropriately to raise the temperature of the steel pipe to $240^{\circ} \mathrm{C}$ within the recorded operating time (see Figure 9a). Next, the domains representing the layers of FBE and CMPP were added to the model and the analysis was resumed in order to simulate cooling of the steel substrate to $190^{\circ} \mathrm{C}$ (see Figure 9b). Reheating of the chamfers was simulated by applying a surface heat flux to the relevant surfaces in the model, defined appropriately in order to replicate reheating to between $140-150^{\circ} \mathrm{C}$ after the time recorded onsite (see Figure 9c).

In the final step of the thermal analysis, the IMPP was included at an initial temperature of $200^{\circ} \mathrm{C}$, in keeping with onsite practice. The model was run to simulate sixteen hours of cooldown which is commensurate with the amount of data recorded by the thermocouples. Three separate models were created for the full, thick hourglass and thin hourglass FJC geometries, respectively, as shown in Figure 8 . 


\subsubsection{Validation of thermal model}

The temperature evolution profiles recorded by the thermocouples (located at the positions indicated in Figure 5) are shown as solid lines in Figures 10 to 12. It can be seen that, as would be expected, temperatures recorded closer to the outer surface of the FJCs at the overlap reduce quicker than those located internally. Owing to thermal conduction through the steel pipe, the temperatures at the weld and toe locations reduce quicker than at the internal thermocouples where the insulating polymer slows down heat flow considerably. This effect is noticeably more pronounced in the full FJC than in the hourglass FJCs, with the temperature reducing quickest in the thin hourglass FJC.

The predictions of the numerical models are shown as dashed lines in Figures 10 to 12. Good agreement is observed between the experimental observations and the numerical predictions, particularly at the weld and toe locations and also at the internal thermocouples, while some discrepancy is observed to develop at the external overlap locations. This can most likely be attributed to the overestimation of the convection transfer coefficient for the external boundary cooling coefficients. It is noticeable that since this discrepancy is more prevalent on the external boundaries rather than in the rest of the model, the majority of temperature loss in the IMPP is due to conduction through the steel, rather than from air convection. Overall, the accuracy of the numerical predictions serves as confirmation of the suitability of the modelling techniques and the material models 
used, and allows for the predicted temperature fields to be applied to the mechanical models.

\subsection{Mechanical modelling}

Numerical modelling of the bend test procedure was performed using Abaqus [20]. For validation of the model, the measured geometry of the test specimens was used, while for the parametric study, nominal dimensions were used. Since wall thickness mismatches were not included in the experimental campaign, their influence was not assessed in the current work.

Temperature-dependent material models were applied in the simulations, with the temperature fields predicted by the thermal modelling mapped to the Abaqus models. The model was validated successfully against the experimental results for ovality and stress distributions, which then allowed a parametric study to be conducted to identify combinations of FJC thickness and cooldown time where buckling is avoided.

\subsubsection{Model geometry and boundary conditions}

The model of the bend test rig is shown in Figure 13, with a combination of shell and solid instances used to model the pipe and coating materials, with two FJCs centred at $20 \mathrm{~mm}$ girth welds. A bare pipe was also modelled in order to provide validation against the bare pipe test performed onsite; a summary of the pipes modelled in the study is shown in Table 2 . 
Analytical rigid instances were used to model the reel former and straightening former, each with a radius of curvature equivalent to those used onsite, respectively. Pin-ended conditions were defined at the anchor end, permitting only rotation in the plane of the rig. Connector elements (see Figure 13) were used to model the cables from the pullhead to the crane with appropriate displacements imposed on them in order to simulate the pipe being bent to the formers across the various analysis steps; these displacements are summarised in Table 3.

Contact interactions were defined between the outer surface of the coating and the former surfaces, with a coefficient of friction of 0.3 to define the tangential behaviour and a pressure overclosure to define the normal behaviour.

Tie constraints were defined between the outer surface of the steel pipe and the inner surfaces of the IMPP and the linepipe coating, thus assuming that delamination would not occur between the steel and the IMPP. In practice, there is a possibility that delamination could occur, but it was not observed during the experimental campaign.

\subsubsection{Material modelling}

As part of the material characterisation campaign conducted by the Innovation Department at Heerema Marine Contractors [16], moduli of elasticity and full stress-strain curves for the various polymer and steel materials used in the pipes were obtained at a number of ambient temperatures and strain rates. A typical set of stress-strain curves is shown in Figure 14 for the IMPP material, with testing 
performed at $5 \mathrm{~mm} / \mathrm{min}$; these curves were converted to true stress and true strain prior to their use in the numerical models. For temperatures outside the tested range, the material curves were based on extrapolation. For the polypropylene materials, an elastic-plastic material model with isotropic hardening was assumed in keeping with previous studies [3-5,21]. Although polypropylene exhibits viscoelastic behaviour in practice, given the strain rates and hold times being modelled in the current study, it was not necessary to model any stress relaxation owing to viscous flow of the material.

The moduli of elasticity of the various coating materials were modelled as temperature-dependent (see Figure 15). Although the Poisson's ratio of polypropylene is affected by temperature, it was found [23] that a value of 0.45 was representative for the range of temperatures considered. The coefficient of thermal expansion for the three polypropylene materials was temperaturedependent and based on manufacturers' recommendations.

The steel linepipe material was also modelled using an elastic-plastic material model albeit with anisotropic kinematic hardening [21,22], based on test data obtained across a range of temperatures [16]. For temperatures outside the tested range, material curves were extrapolated based on derating the material in accordance with DNV guidelines [15]; a summary of steel yield strengths corresponding to increasing temperatures is given in Table 4. As can be seen from the resulting true stress-true strain curves shown in Figure 16, the well-defined 
yield point characteristic of carbon steels at room temperature has been preserved across all temperatures in the current analysis, in keeping with [9-13]. The constitutive relationship for the welds was assumed to be similar to that of the parent steel, albeit with isotropic hardening and a strength overmatch of $80 \mathrm{~N} / \mathrm{mm}^{2}$ based on previous experience [3]. The modulus of elasticity of the steel materials is not explicitly defined in API [6] or DNV guidance [15], and therefore was assumed to be $210000 \mathrm{~N} / \mathrm{mm}^{2}$ with a Poisson's ratio equal to 0.3 . The coefficient of linear expansion was set equal to $13 \times 10^{-6}$.

\subsubsection{Elements and meshing}

In the interests of computational efficiency, the mechanical model employed a combination of quadrilateral shell S4R elements for the steel pipe and solid C3D8R elements for the thicker coating materials. The steel pipe elements were in fact composite layups in order to include the thin layers of FBE and CMPP. A nominal element size of $15 \mathrm{~mm}$ was used, with the mesh density increased around the area of interest at the weld.

\subsubsection{Mapping of temperature fields}

The thermal analysis was performed using two-dimensional axisymmetric models with triangular meshes, while the mechanical analysis used three-dimensional solid brick and quadrilateral shell elements. In order to map the temperature field correctly, an algorithm was developed whereby the COMSOL temperature field 
was centred on a weld plane and then translated and rotated to cylindrical coordinates. A least-squares node-matching routine then identified the nodes in the COMSOL mesh closest to each node in the Abaqus mesh within longitudinal neighbourhoods of $100 \mathrm{~mm}$. The resulting field was then inputted as a discrete field into the Abaqus model. An example of the result of running the algorithm is shown in Figure 17, with the COMSOL temperature output on the left hand side and the resulting temperature field in Abaqus shown on the right hand side. For validation of the numerical models against the experiments, temperature fields were outputted at the appropriate cooldown times related to the time after IMPP application recorded during the bend tests.

Since there was a half hour to an hour difference in application time between the two FJCs for a particular test pipe, and thus a noticeable difference in temperature, separate temperature fields were mapped around the two joints as appropriate.

\subsubsection{Analysis procedure}

A static analysis using nonlinear geometry was employed, divided into a number of steps, as shown in Figure 18: i) firstly, the temperature field was applied to the model; ii) next the pipe was bent to the reel former and held; iii) the temperature field was then set equal to the appropriate ambient temperature (either that recorded onsite for the validation study, or $20^{\circ} \mathrm{C}$ for the parametric study) in order to simulate the pipe and FJCs cooling down; iv) next, the pipe was released, then v) bent to the straightening former, and finally vi) released again, thus completing the 
first bend cycle. The model simulated five full bending cycles in total (the latter four all with the temperature field set equal to the appropriate ambient temperature). As can be seen in Figure 18, after a full bend cycle there is a noticeable amount of plastic deformation present in the pipe after straightening; limiting this plastic deformation and avoiding buckling of the pipe and tearing of the coating are the two main challenges posed by the reel-lay procedure.

\section{Results and comparisons}

In this section, the results of the bend tests are discussed, and comparison is made with the predictions of the numerical model.

\subsection{Pipe deformation, buckling and ovality}

Pipe 1, a bare pipe with no FJCs, was tested first in the bend rig as a control specimen, whereupon it buckled at the first bend to the reel former, as shown in Figure 19a; this early onset buckle can be attributed to the stiffness mismatch between the full linepipe coating and the bare steel pipe causing strains to concentrate within the bare steel. It can also be seen that the point of initiation of buckling is located to the left of the weld. The strain field predicted by the numerical model is shown in Figure 19b, where the strain concentration can indeed be observed in the uncoated region of the pipe. It can be seen that the pipe was also predicted to buckle after the first bend to the reel, albeit with the point of initiation of buckling located closer to the weld; this discrepancy in buckle location can most 
likely be attributed to a localised thinning of the pipe wall in the area around the buckle. It can be seen that, in areas in the steel pipe away from the buckle, the tensile strain is approximately $2.5 \%$, in keeping with analytical predictions.

Despite the presence of the polymer coating, one of the field joints on Pipe 2 (with the thin hourglass FJC) also buckled on the first bend to the reel. During initial simulations prior to the test campaign, ovalities in excess of $10 \%$ were expected; based on previous experience [24] this level of ovality is a strong predictor of the occurrence of buckling. The buckled field joint is shown in Figure 20a; as can be seen, there is noticeable liftoff from the reel former. In Figure 20b, the corresponding numerical prediction of stress is shown, with rippling observable in the compression zone.

Pipes 3 and 4 (with thick hourglass FJCs and full FJCs, respectively) did not buckle throughout the five bending cycles; the numerical models also predicted that no buckling would occur. In Figure 21, the ovalities recorded along the length of Pipe 3 after the first bend to the reel are compared to corresponding numerical predictions, with the ovalities calculated according to Eq.(1). The two peaks in the ovality distributions coincide with the location of the field joints. As can be seen, there is particularly good agreement in the region around the field joint furthest from the anchor end, while the predictions of ovality are conservative at the field joint closest to the anchor end. This can be attributed to some relaxation of contact stress towards the anchor end during the simulation as the point of contact 
progresses along the pipe. Similar accuracy was obtained across all the tested pipes, thus increasing confidence in the ability of the numerical model to predict pipe deformations and ovalities but most importantly, whether the field joints can withstand five full bending cycles. The results of the experimental investigation and the numerical analysis indicate that, provided the correct FJC thickness is applied, reeling of pipelines with 100 mm-thick MLPP coatings is indeed achievable.

\subsection{Stress whitening}

During testing of the specimens with FJCs, stress whitening was observed, whereby the molecular chains within the IMPP becomes damaged due to excessive tensile stresses causing plastic deformation, with holes and tears forming as the molecular structure is altered [25]. Light incident upon the affected zones is then diffused and scattered more readily, appearing as white discolorations on the surface of the polypropylene. In the following discussion, comparisons are made after the first bend to the reel former and holding in position overnight, i.e., after the field joint has cooled down fully.

Owing to the inherent difficulty of installing stress-measuring instrumentation into the coating and retrieving it afterwards unscathed, visual identification of stress whitening was used as an indicator of tensile stress concentrations within the IMPP material. In Figure 22, the appearance of stress whitening in the thick hourglass FJC is compared to the numerical prediction of the principal stress field. Given that 
the yield stress is approximately $16.0 \mathrm{~N} / \mathrm{mm}^{2}$ and the maximum stress predicted in $21.0 \mathrm{~N} / \mathrm{mm}^{2}$, it can be seen that the location of areas where plastic deformation has occurred most agrees very well with the location of stress whitening observed onsite above the chamfer toes.

In the case of the thin hourglass FJC of Pipe 2, as can be seen in Figure 23a, the level of stress whitening was not as prevalent or as noticeable, indicating that much less plastic deformation has occurred than in the thick hourglass FJC. This is in agreement with the predicted stress field shown in Figure 23b where the maximum stress is $13.9 \mathrm{~N} / \mathrm{mm}^{2}$, suggesting that the material has not yielded yet (although in practice some polymer chains may have been damaged already when the material was hotter and therefore less strong, in keeping with the curves shown in Figure 14). While it may seem counterintuitive that less stress whitening has occurred in the thinner FJC, this can be explained by considering the reduction in longitudinal strain on the outer surface of the thin hourglass FJC since it is closer to the neutral axis of the section than the outer surface of the thick hourglass FJC. It can be seen that the areas of peak stress above the chamfer toe coincide with the lightest, and therefore more stressed, areas on the external surface of the tested pipe. One possible method by which these stress concentrations could be removed is by provided a more shallow chamfer angle; however, in practice this would lead to onerously long chamfers. 
As can be seen in Figure 24a, stress whitening was observed after the testing of Pipe 4 (with full FJCs); stress concentrations were also predicted in the numerical model, as shown in Figure 24b. Although the level of agreement is not as strong as in the hourglass FJCs, particularly with respect to the location of the stress concentrations, the level of stress predicted by the numerical model in the whitened areas is commensurate with the yield stress of the material.

Finally, in addition to the three pipes with hot tie-in field joints, Pipe 5 (with full FJCs) was tested after it had fully cooled down to the ambient temperature. As can be seen in Figure 25a, there was no evidence of stress whitening visible in this specimen, and as shown in Figure 25b, the numerical model also predicted a uniform stress field with no concentrations, with maximum stresses of approximately $15.0 \mathrm{~N} / \mathrm{mm}^{2}$ in the IMPP.

From these observations, it is surmised that the bending of the steel pipe when it is still hot and weakened leads to higher strains and deformation around the field joint. The thin hourglass field joint would have cooled quicker than the thick hourglass field joint, allowing the steel to regain relatively more strength and thus the amount of strain induced is limited. The increased deformation in the thick field joint led to higher strains and stresses in Pipe 3, which can be observed upon comparison of Figures 22b and 23b.

In the each of the three cases of hot tie-in field joints, it can be seen that stress concentrations and areas of stress whitening occur above the chamfers, particularly 
above the chamfer toe. This can be attributed to there being a stiffness mismatch either side of the chamfer that causes stress to concentrate at this point; however, the transition between the IMPP field joint coating and the MLPP linepipe coating occurs quite gradually over the length of the chamfer (approximately $175 \mathrm{~mm}$ ), and so sudden peaks in stress would not be expected.

Upon inspection of the evolution of the distribution of ovality along the length of the pipe specimen during the bend test, a correlation between peak ovality gradient and the peaks in stress was apparent. In Figure 26, the distribution of ovality gradient along the length of Pipe 3, as predicted by the numerical model, is shown. The locations of the chamfers and field joints are also overlaid on the graph. It can be seen that areas of peak ovality gradient coincides with the toes of the chamfer, where stress whitening was also readily observable in Figure 22a. In addition, although stresses close to the yield strength were predicted in the full FJCs by the numerical model of the pipe that was bent after fully cooling down, since the stress distribution and also ovality distribution were quite uniform, i.e., with a small gradient, there was no stress whitening visible. This agreement between peak ovality gradient and areas of stress whitening can be attributed to the higher levels of strain associated with sudden large deformations in the steel pipe, which would cause commensurate large strains, and hence stresses, in the coating materials.

\subsection{Coating failures}


During the bend test of Pipe 1, the MLPP linepipe coating cracked along the chamfer as shown in Figure 27a. Stress concentrations were also predicted along the chamfer on the anchor end of the pipe by the numerical model, as shown in Figure 27b.

\subsection{Parametric study}

As demonstrated by the comparisons between the experimental observations and the numerical results, the thermal and mechanicals models are capable of accurately predicting the behaviour of hot tie-in field joints in bending. With the model validated, a parametric study was conducted varying the thickness of the FJCs and the amount of cooldown time. Bend tests on pipes with FJCs thicknesses from $20 \mathrm{~mm}$ up to a full FJC and cooldown times from one hour up to 24 hours were simulated and assessed to ascertain whether the five full bend cycles could be completed without the pipe buckling. The results of the parametric study showed that a minimum FJC thickness was required in order to avoid buckling at all, since the thinner FJCs did not provide adequate stiffness around the field joint. Once this minimum thickness requirement was satisfied, then optimisation with respect to the time saved could be conducted. It was found that the thicker FJCs (close to a full FJC) required too long to cool down to offer any meaningful time savings. However, an optimum mid-range thickness existed that offered significant time savings when compared to current practice. 


\section{Conclusions}

Finite element models simulating the thermal and mechanical behaviour of hot tiein field joints during coating application and bending operations have been developed. Experimental investigations recording the temperature evolution profiles within the field joint coatings after pouring and the mechanical behaviour of the field joints during bend testing were used as a basis for calibration and validation of the numerical models. Three separate field joint coating geometries were tested in order to examine the influence of coating thickness on the overall behaviour of the field joint.

Thermal modelling in COMSOL Multiphysics employed temperature-dependent thermal properties obtained from material characterization testing. It was found that it was necessary to model internal air cooling in the test specimens, which would not normally be required when modelling longer pipeline sections. Close agreement was observed upon comparison of temperature evolutions recorded onsite with those predicted by the numerical models, allowing for the predicted temperature fields to be subsequently applied to mechanical models.

Numerical models were developed in Abaqus to simulate bend testing of the various pipe specimens, again employing temperature-dependent material models obtained from material characterisation. Temperature fields obtained from the thermal numerical models were mapped onto the mechanical models and the 
process of bend testing over five full bend cycles was simulated. The numerical predictions for pipe ovality and coating stress distributions were compared with the experimental results, with close agreement observed, thus demonstrating the accuracy of separating the thermal and mechanical modelling. It was also found that ovality gradient can be used as a predictor of the occurrence of stress concentrations in the coating materials. The numerical analysis, coupled with the results of the experimental investigation, showed that reeling of pipes with 100 mm-thick coating is indeed possible provided an appropriate FJC thickness has been specified.

The successful validation of the numerical models allowed for an extensive parametric study to be conducted, varying the field joint coating thickness and the cooldown times provided after application of the IMPP. It was found that an optimal FJC thickness existed that balanced the quicker cooldown times associated with thinner FJCs with the material strength benefits of thicker FJCs. The results of the study showed that use of this optimal FJC thickness can result in significant time savings when conducting reeling operations in practice.

\section{Acknowledgements}

The authors wish to thank the team at the Innovation Department of Heerema Marine Contractors for their assistance during the planning and execution of the 
experimental campaign, and also to David Haldane and the technical staff at Heriot Watt University for their support throughout the experimental campaign.

\section{References}

[1] Kyriakides, S., Corona, E. 2007. Mechanics of Offshore Pipelines: Volume 1 Buckling and Collapse, Elsevier, Oxford, UK and Burlington, Massachusetts.

[2] Smith, S.N. \& Clough, T. 2010. Deepwater pipeline installation by reel-lay method. Proceedings of the Offshore Technology Conference 2010, 3-6 May 2010, Houston, TX.

[2] Karjadi, E., Boyd, H., van Rooijen, R., Demmink, H., Balder, T. 2013. Development of Aegir reeling pipeline analyses by test validation, Proceedings of the $32^{\text {nd }}$ International Conference on Ocean, Offshore and Arctic Engineering, 914 June 2013, Nantes, France.

[3] Ridolfi, G., Boyd, H., Karjadi, E., Demmink, H., McCann, F., de Bode, A. 2015. Extension of the reel-ability envelope of the Aegir: synergy between analysis and full-scale testing. Proceedings of the $25^{\text {th }}$ International Ocean and Polar Engineering Conference, 21-26 June 2015, Hawaii, USA.

[4] Crome T. 1999. Reeling of pipelines with thick insulation coating: finiteelement analysis of local buckling. Proceedings of the Offshore Technology Conference 1999, 3-6 May 1999, Houston, TX. 
[5] Liu, Y., Kyriakades, S. 2017. Effect of geometric and material discontinuities on the reeling of pipelines. Applied Ocean Research, 65:238-250.

[6] American Petroleum Institute. 2004. API 5L: Specification for Line Pipe, API, Washington.

[7] Det Norske Veritas. 2011. DNV-RP-F102: Pipeline Field Joint Coating and Field Repair of Linepipe Coating. DNV, 2011.

[8] Det Norske Veritas. 2011. DNV-RP-F106: Factory Applied External Pipeline Coatings for Corrosion Control. DNV, 2011.

[9] McCann, F., Gardner, L., Kirk, S. 2015. Elevated temperature material properties of cold-formed steel hollow sections, Thin-Walled Structures, 90:84-94. [10] Outinen, J., Kaitila, O., Mäkeläinen, P. 2001. High-temperature testing of structural steel and modelling of structures at fire temperatures. Research report TKK-TER-23. Helsinki, Finland: Helsinki University of Technology, Laboratory of Steel Structures; 2001.

[11] Qiang, X., Bijlaard, F. S. K., Kolstein, H. 2013. Elevated-temperature mechanical properties of high strength structural steel S460N: Experimental study and recommendations for fire-resistance design. Fire Safety Journal. 55:15-21.

[12] Li, H-T, Young, B. 2017. Material properties of cold-formed high strength steel at elevated temperatures. Thin-Walled Structures, 115:289-299. 
[13] Heidarpour, A., Tofts, N.S., Korayem, A.H., Zhao, X.L., Hutchinson, C.R. 2014. Mechanical properties of very high strength steel at elevated temperatures, Fire Safety Journal, 64:27-35.

[14] Winful, D., Cashell, K., Afshan, S. Pargeter, R.J. 2017. Material Properties of high strength steel under fire conditions. Proceedings of Eurosteel 2017, September 13 - 15, 2017, Copenhagen, Denmark.

[15] Det Norske Veritas. 2013. DNV-OS-F101: Submarine Pipeline Systems. DNV, 2013.

[16] Boyd H., Ridolfi G., 2014. Material Fingerprinting for Coatings. Proc Offshore Pipeline Technology Conference, Amsterdam, 2014.

[17] COMSOL, Inc. 2011. COMSOL Multiphysics 4.2a. COMSOL, Inc. 2011.

[18] Weidenfeller, B., Höfer, M., Schilling, F.R. 2004. Thermal Conductivity, thermal diffusivity and specific heat capacity of particle filled polypropylene. Composites; Part A, 35:423-429.

[19] McAdams, W.H. 1954. Heat Transmission, $3^{\text {rd }}$ ed., McGraw-Hill, New York, NY.

[20] Abaqus. 2012. ABAQUS analysis user's manual, v6.12.3. USA: Dassault Systems Simulia Corp., Providence; 2012.

[21] Karjadi, E., Boyd, H., Demmink, H., Thibaux, P. 2015. Reeling pipeline material characterization - testing, material modeling and offshore measurement 
validation, Proceedings of the $34^{\text {th }}$ International Conference on Ocean, Offshore and Arctic Engineering, 31 May-5 June 2015, St. Johns, Canada.

[22] Liu, Y., Kyriakades, S., Hallai, J.F. Reeling of pipes with Lüders bands. International Journal of Solids and Structures, 72:11-25.

[23] Bayar, S., Dalate, F., Liaw, B. 2012. Effect of temperature on mechanical properties of nanoclay reinforced polymeric nano-composites - Part I: Experimental Results. US Army TARDEC Technical Report No. 22857.

[24] Karjadi, E., Boyd, H., van Rooijen, R., Demmink, H., Balder, T. 2013. Development on Aegir reeling pipeline analyses by test validation, Proceedings of the $32^{\text {nd }}$ International Conference on Ocean, Offshore and Arctic Engineering, 914 June 2013, Nantes, France.

[25] Pae, K. D., Chu, H.-C., Lee, J. K., Kim, J.-H. 2000. Healing of stresswhitening in polyethylene and polypropylene at or below room temperature. Polymer Engineering \& Science, 40(8):1783-1795. 


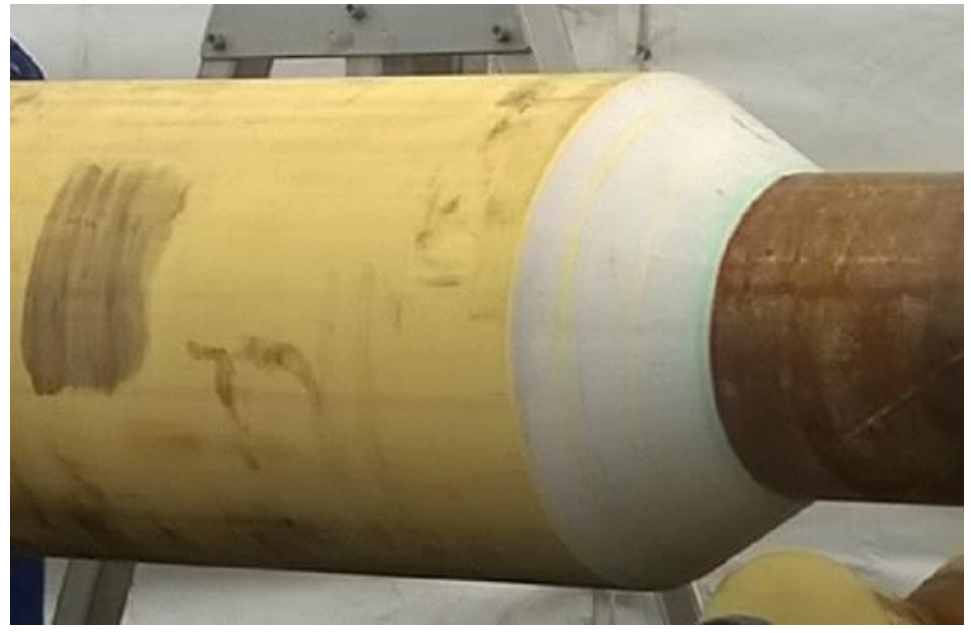

Figure 1: Linepipe coating cut back away from weld, with a chamfer included. 


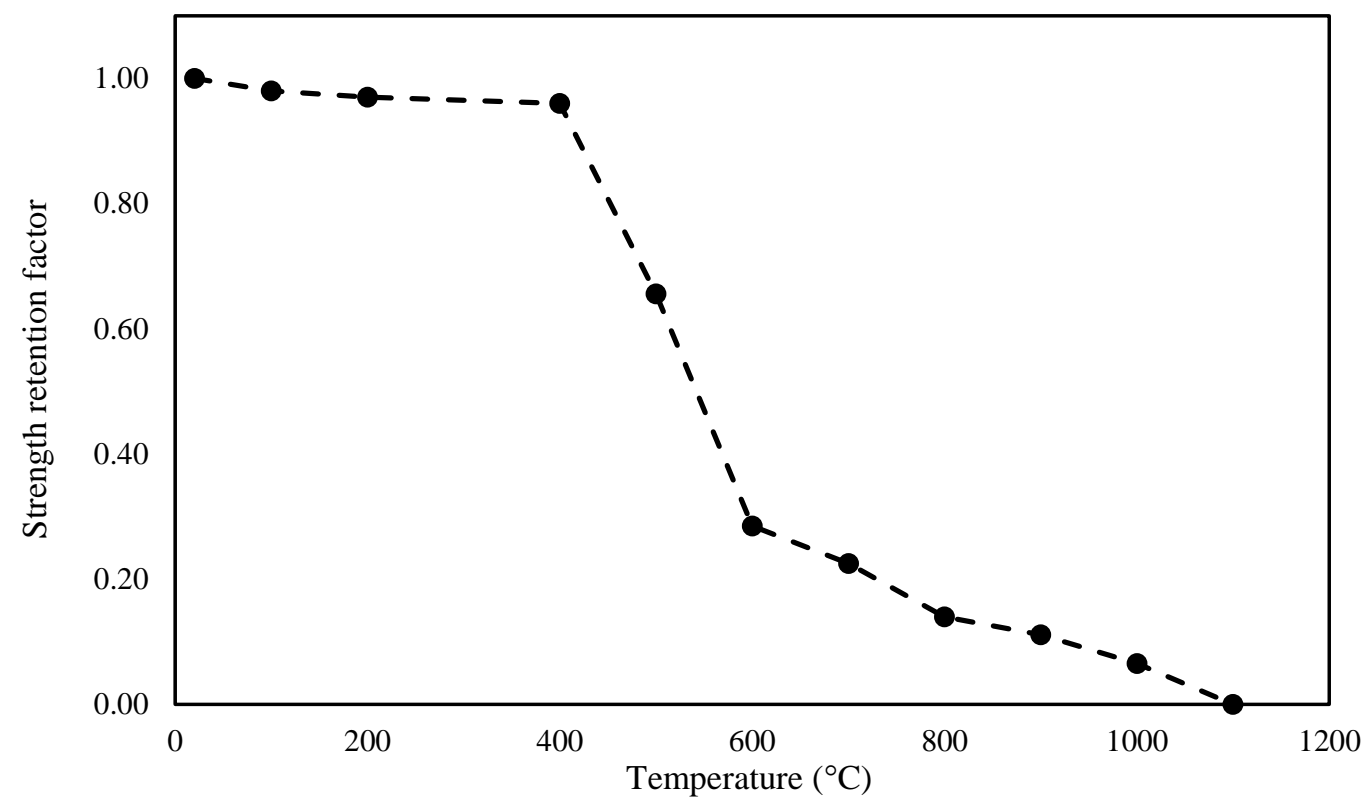

Figure 2: Typical graph of strength retention with increasing temperature for structural steels. 
a)

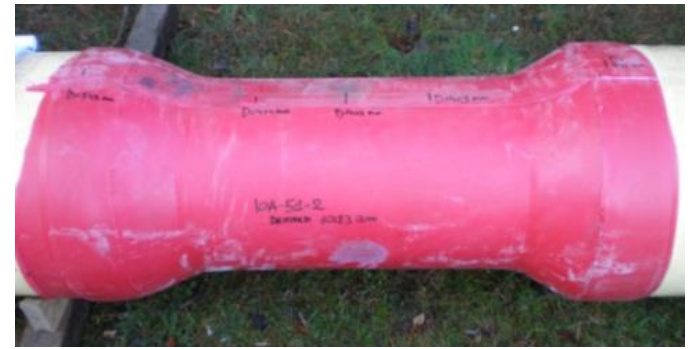

b)

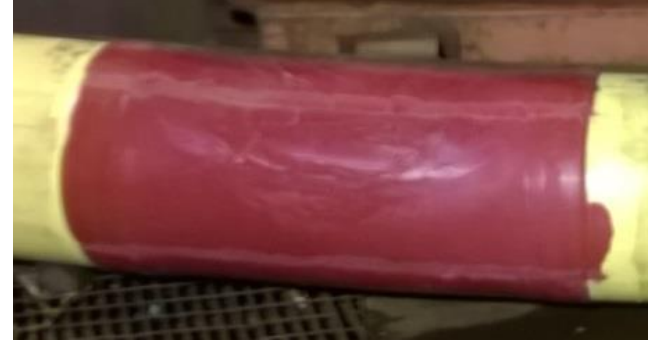

Figure 3: a) hourglass field joint coating; b) full field joint coating. 


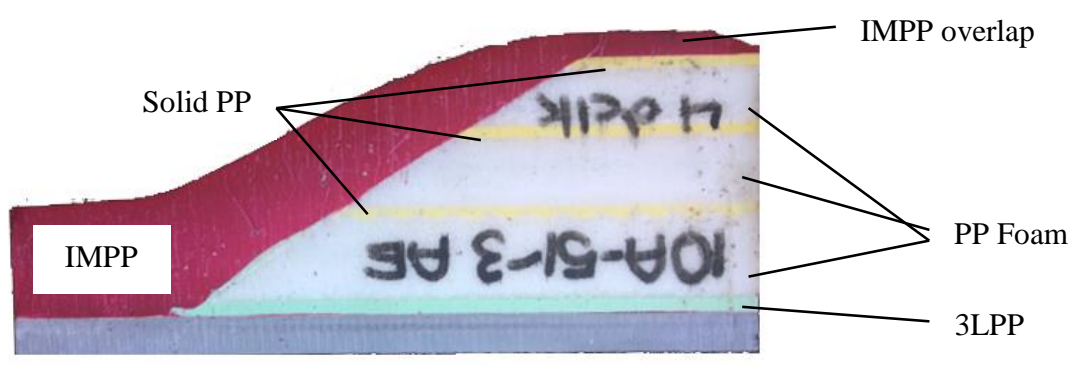

Figure 4: Cut section of 9LPP linepipe coating and IMPP field joint coating. 
a)

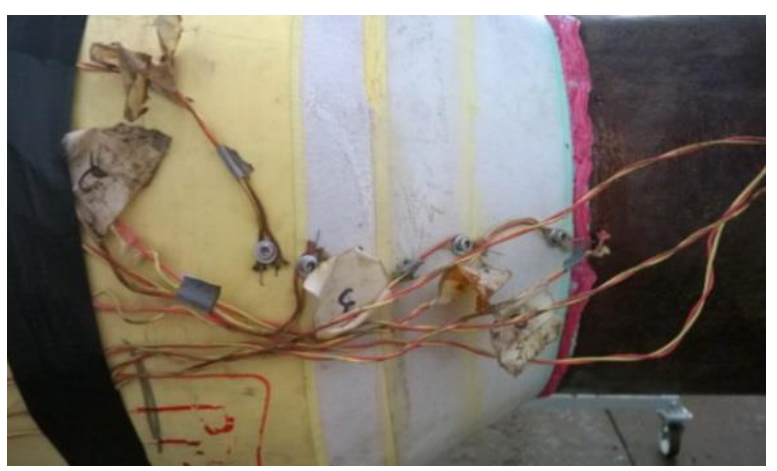

b)

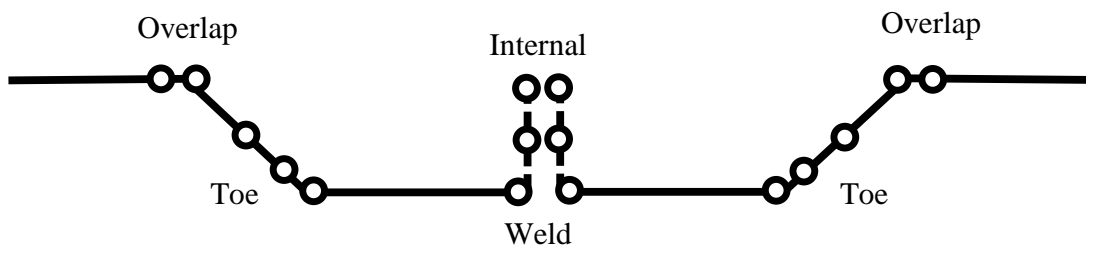

Figure 5: a) thermocouples attached to the chamfers onsite; b) schematic of thermocouple locations within the FJC. 


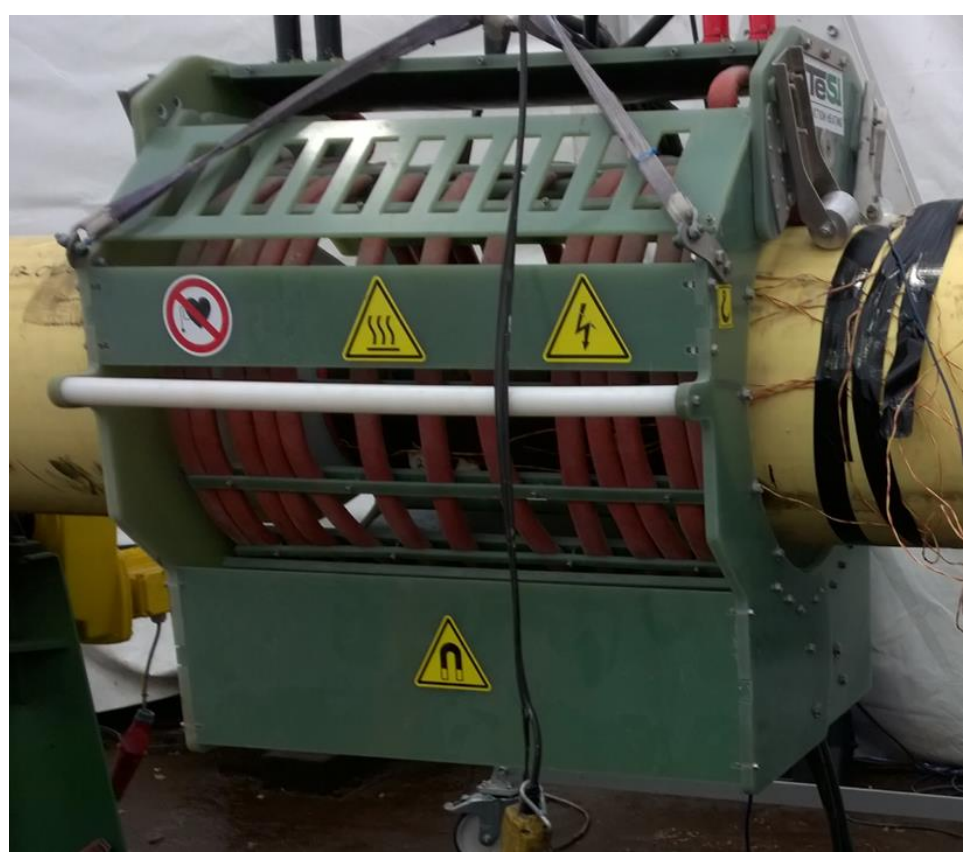

Figure 6: Induction heater installed around field joint. 


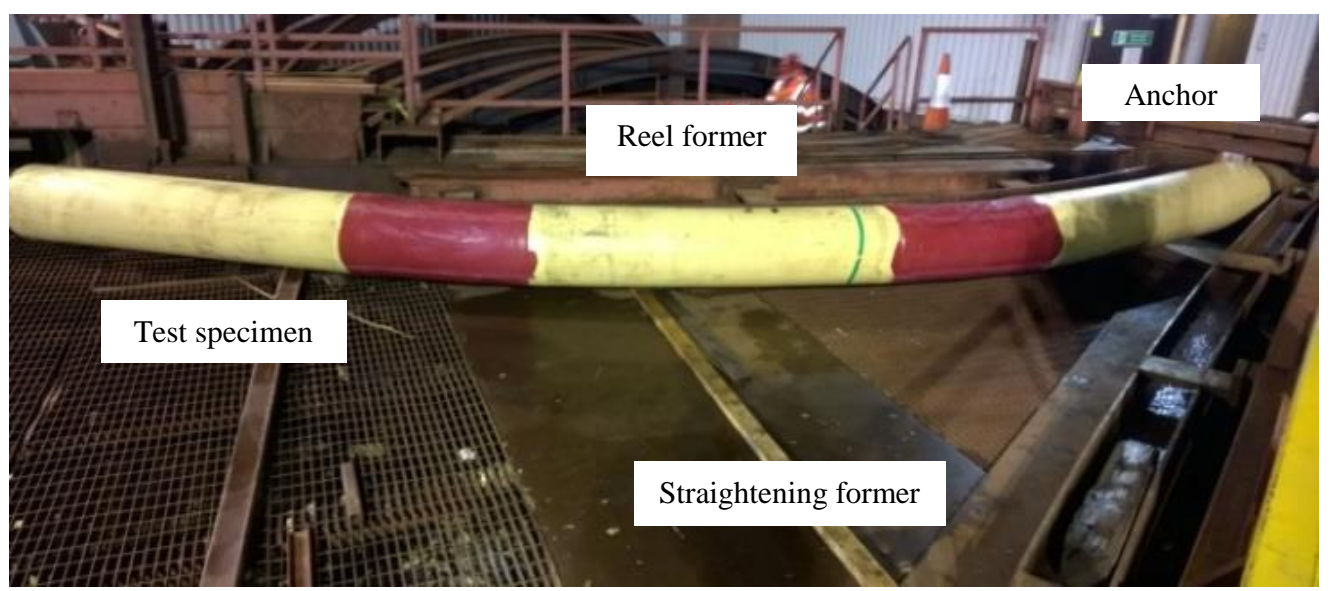

Figure 7: Bend test rig at Heriot Watt University, with a test specimen bent to the reel former. 
Thin hourglass field joint

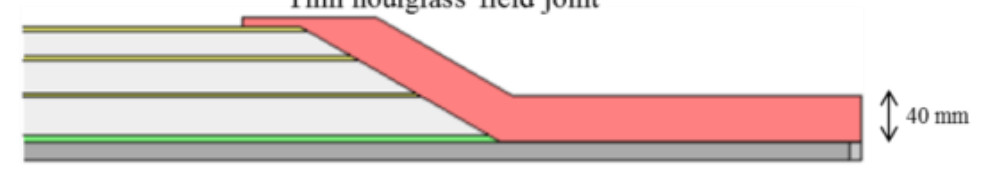

Thick hourglass field joint

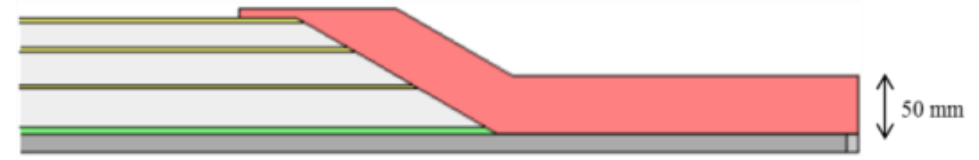

Full field joint

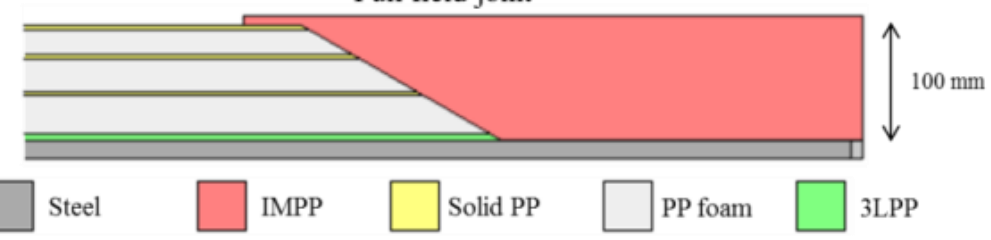

Figure 8: Modelling of field joints in COMSOL. 
a)

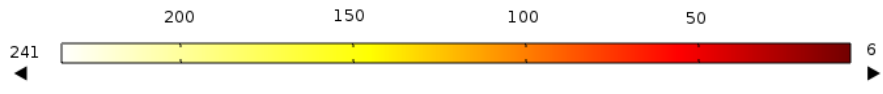

b)

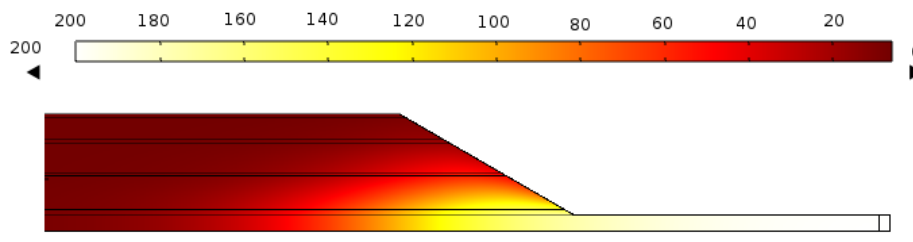

c)

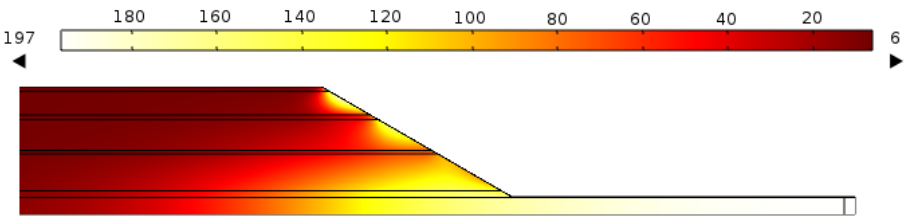

Figure 9: Results of thermal modelling steps; a) induction heating of steel pipe; b) cooldown after application of FBE and CMPP layers; c) reheating of chamfers. 


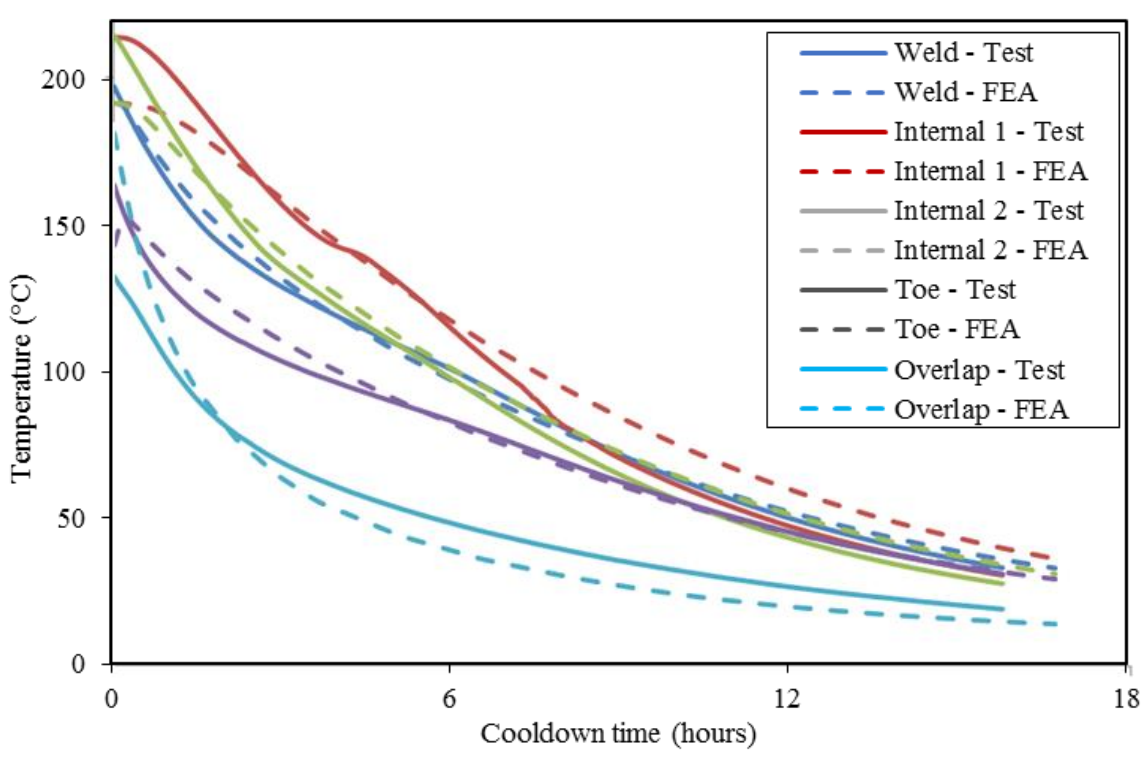

Figure 10: Experimental and numerical temperature evolutions for the full FJC specimen. 


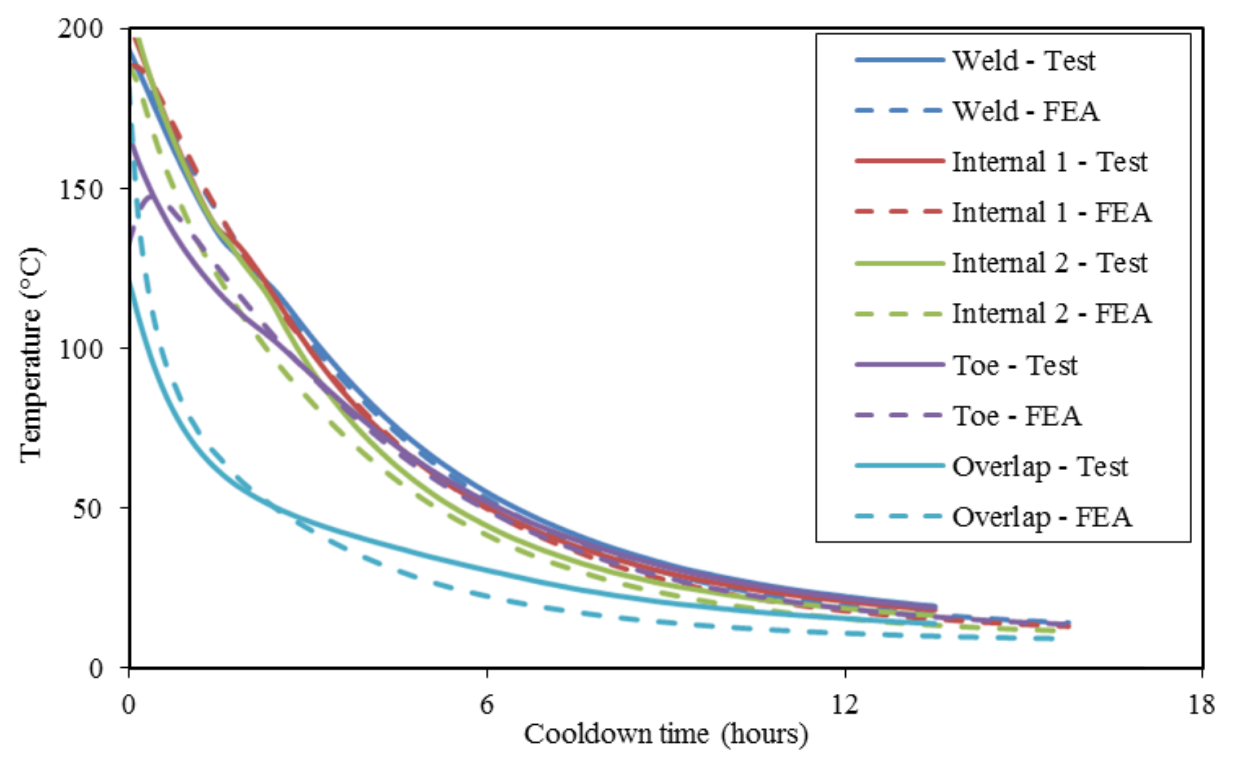

Figure 11: Experimental and numerical temperature evolutions for the thick hourglass FJC specimen. 


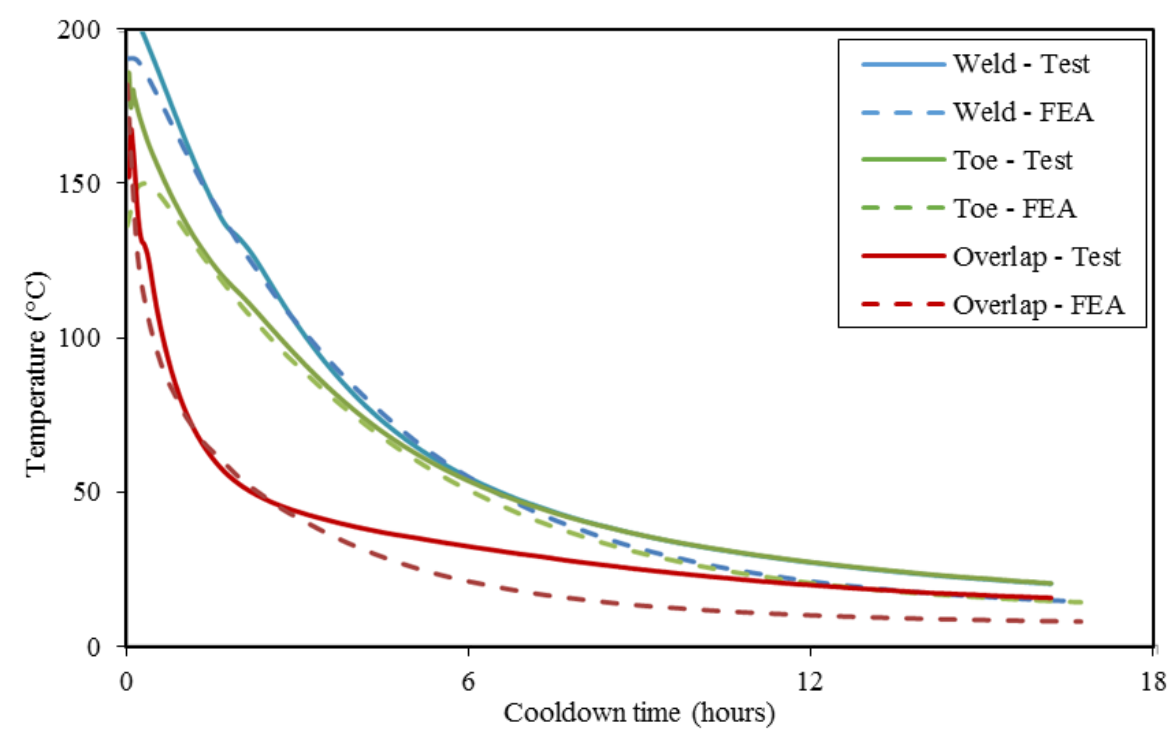

Figure 12: Experimental and numerical temperature evolutions for the thin hourglass FJC specimen. 


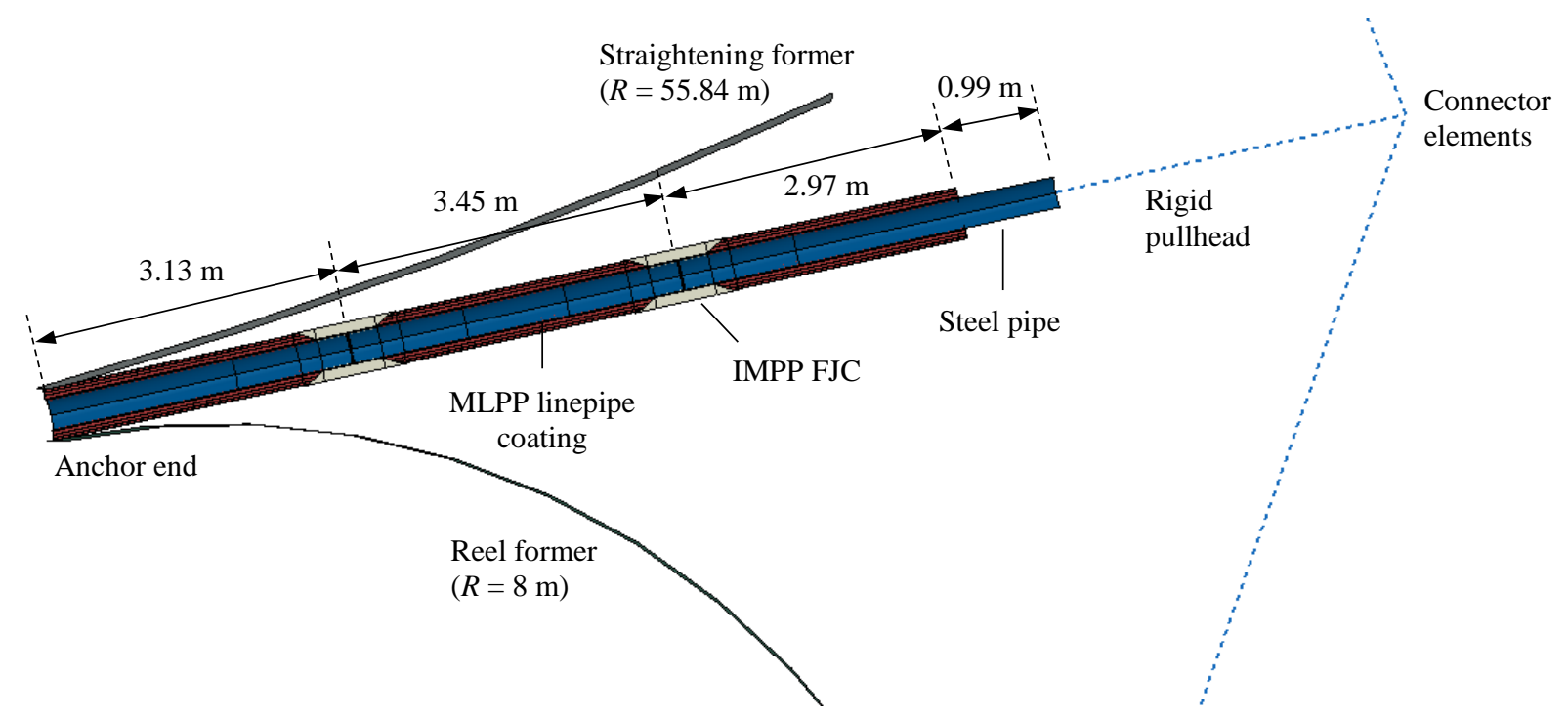

Figure 13: Model of the bend test rig and pipe specimen in Abaqus. 


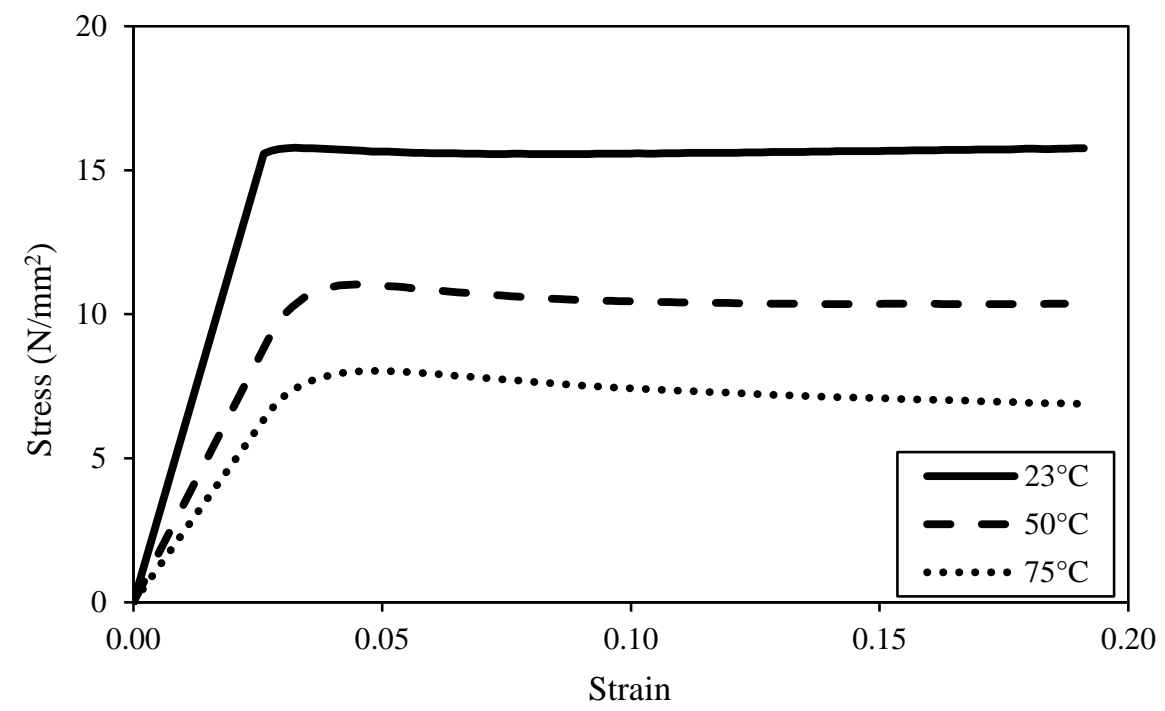

Figure 14: Stress-strain curves for the IMPP material obtained from tensile testing at $5 \mathrm{~mm} / \mathrm{min}$ across a range of temperatures. 


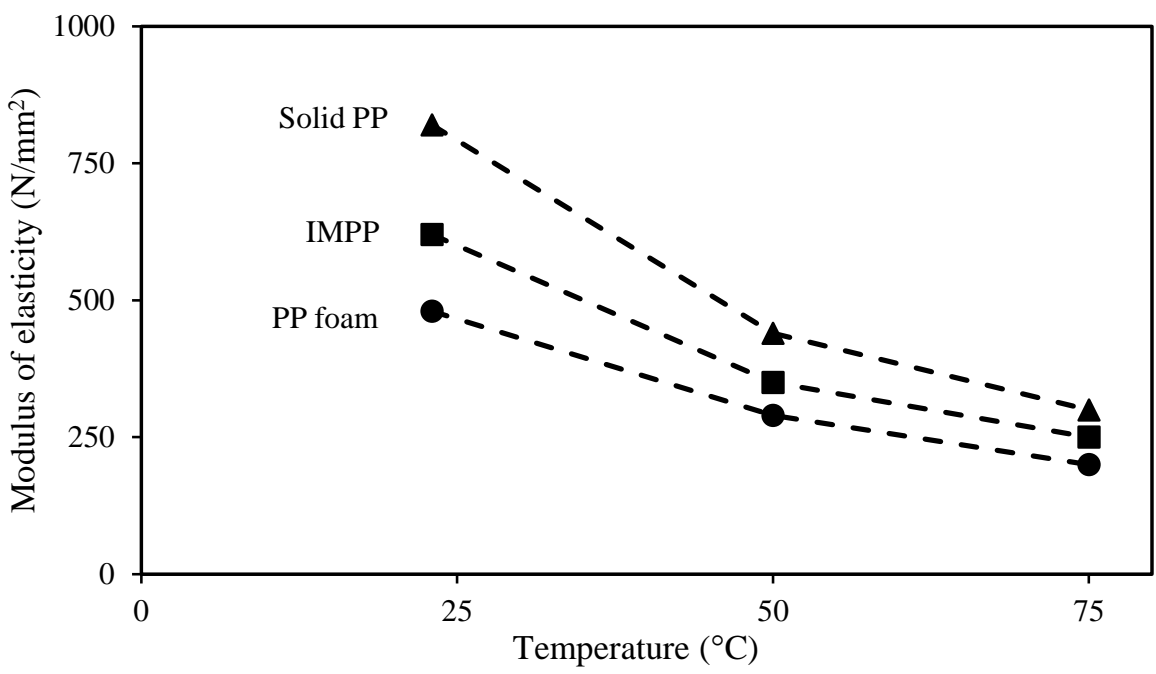

Figure 15: Moduli of elasticity of polymer coating materials. 


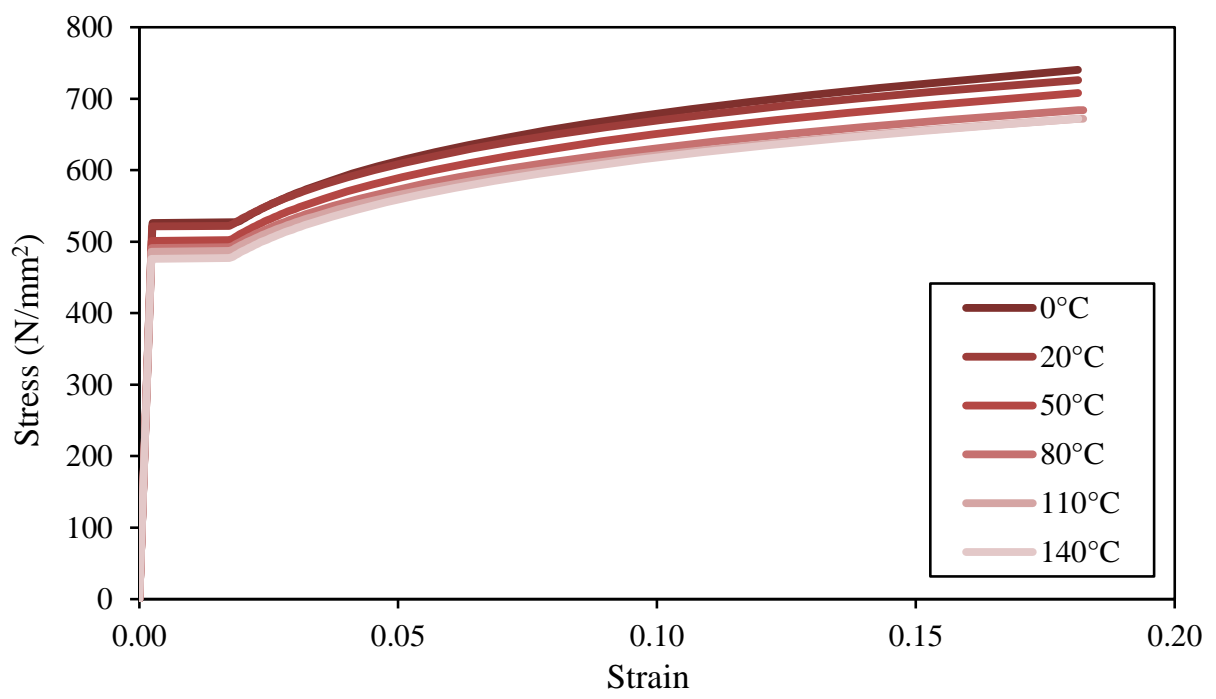

Figure 16: Stress-strain curves for X65 steel at a range of temperatures. 


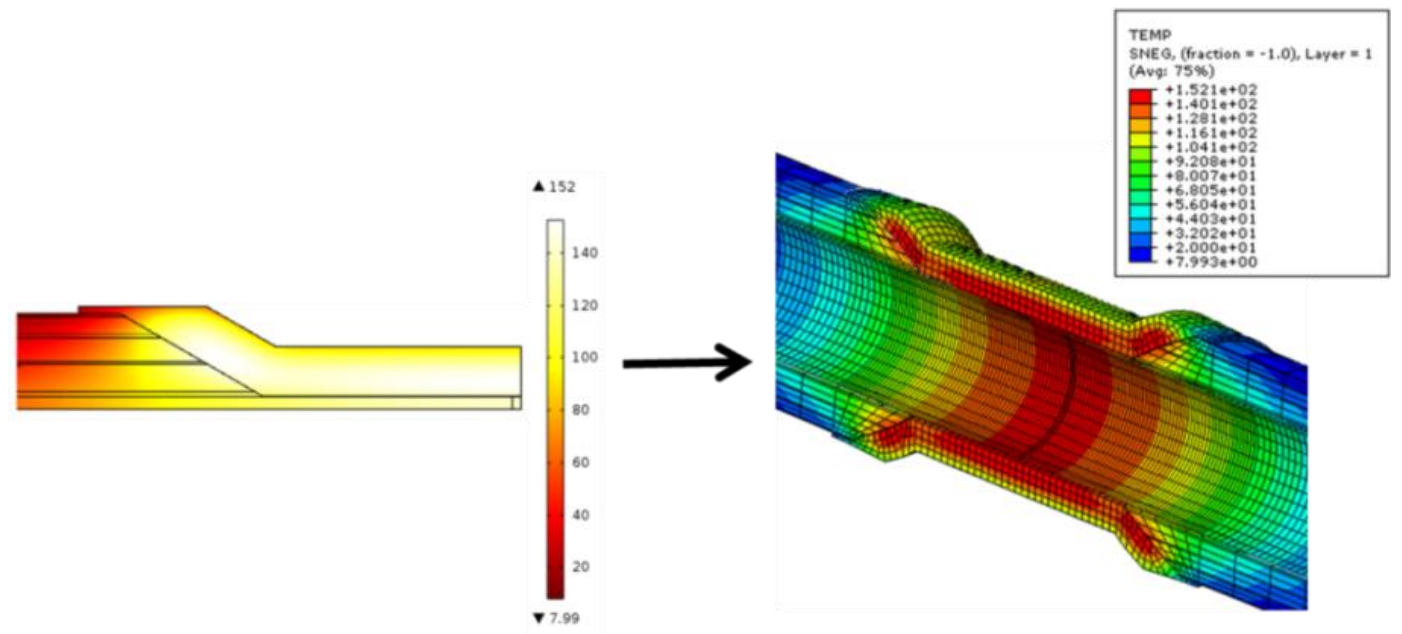

Figure 17: Example of transferral of COMSOL temperature output to a discrete field in Abaqus. 


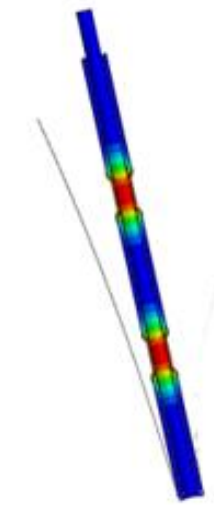

i) apply temperature field

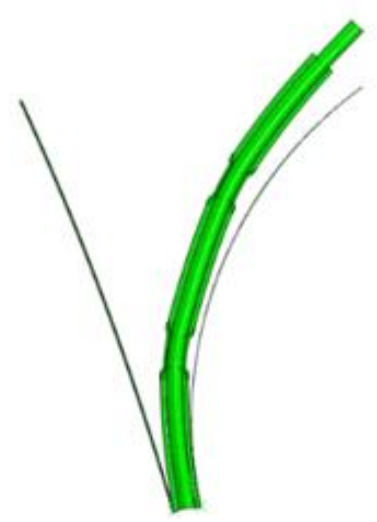

iv) release

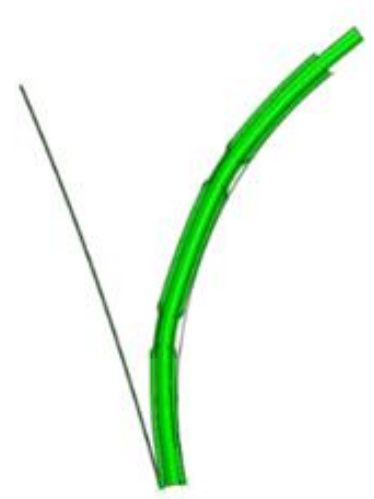

ii) bend

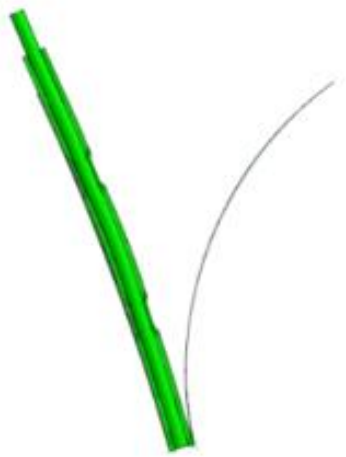

v) straighten

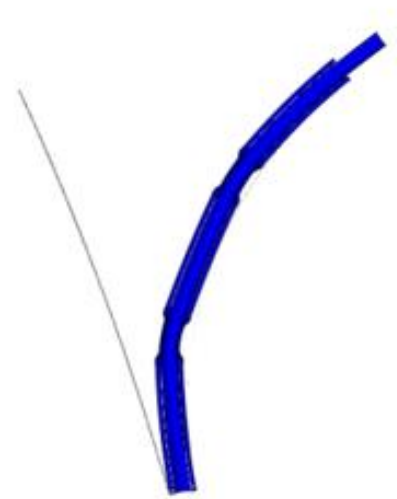

iii) set to ambient temperature

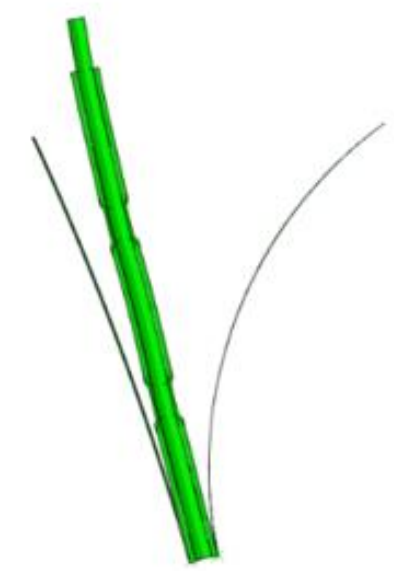

vi) release

Figure 18: Bend cycle steps modelled in Abaqus. 
a)

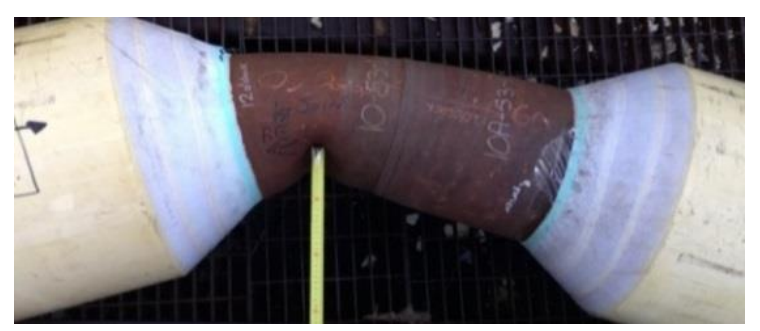

b)
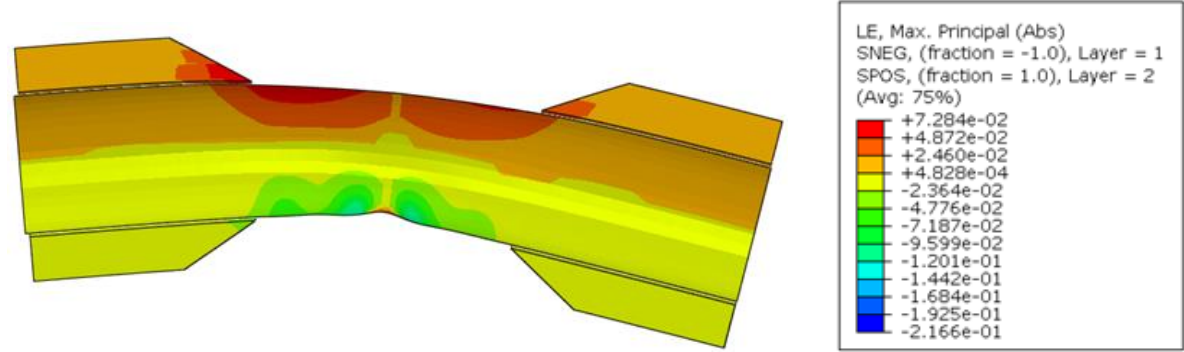

Figure 19: Bending of Pipe 1; a) experimental observation and b) numerical prediction of strain field. 
a)

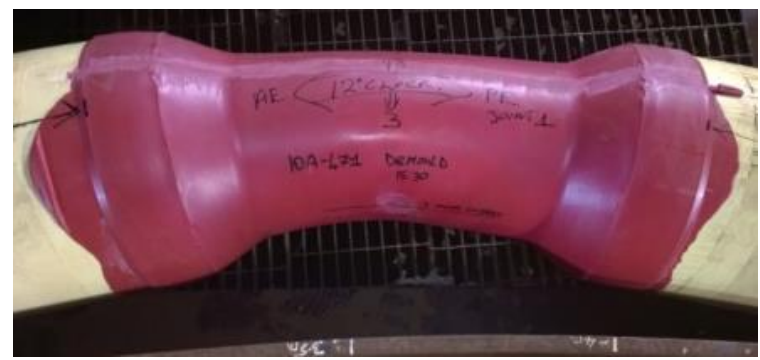

b)

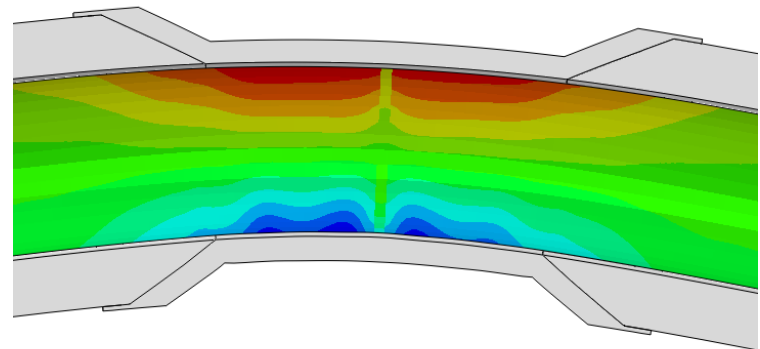

Figure 20: Bending of Pipe 2; a) experimental observation, b) simulated strain field with rippling observable in the compression zone. 


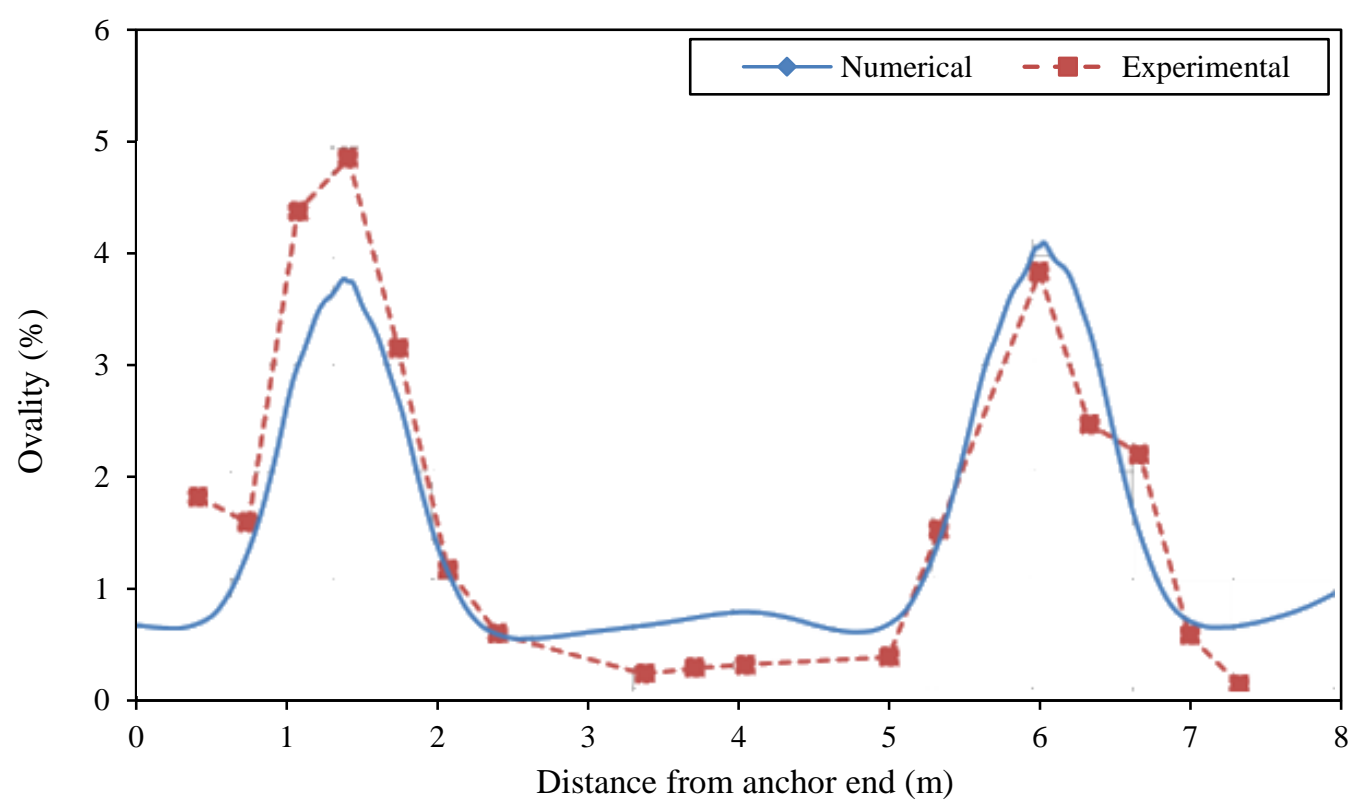

Figure 21: Comparison of measured and predicted ovality distributions in Pipe 3 after the first bend to the reel former. 
a)

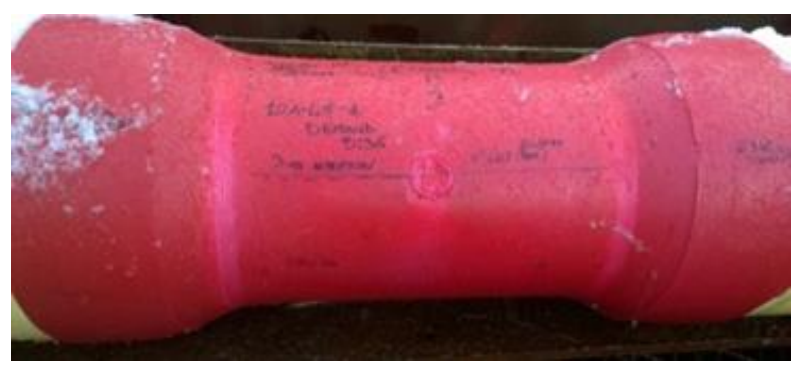

b)

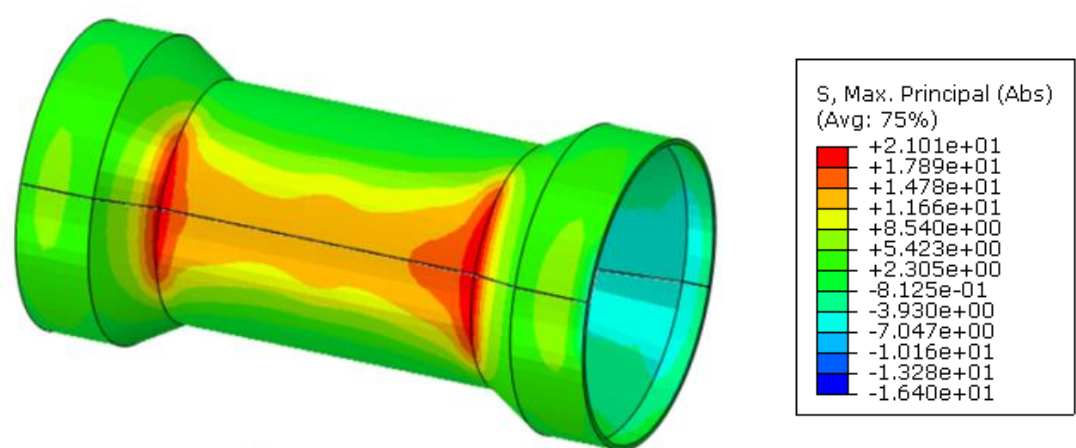

Figure 22: Pipe 3 - comparison of a) stress whitening observed during test with b) numerical prediction of stress. 
a)

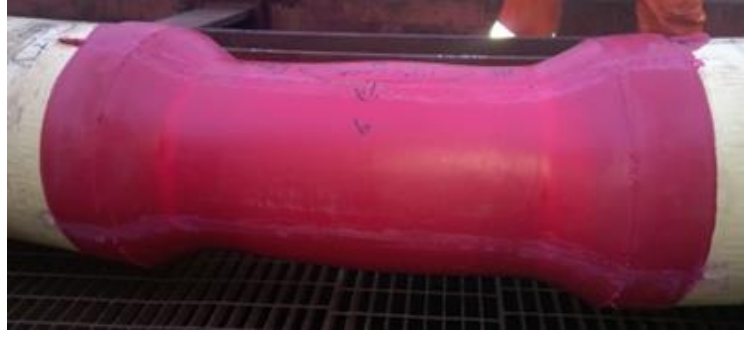

b)

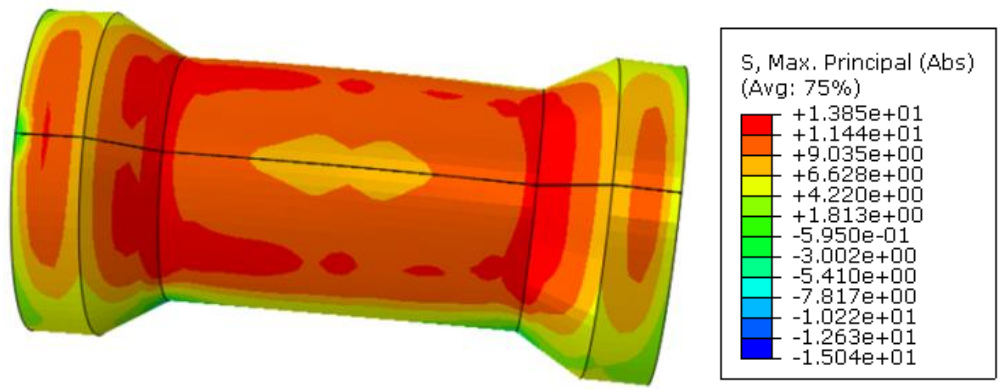

Figure 23: Pipe 2 - comparison of a) stress whitening observed during test with b) numerical prediction of stress. 
a)

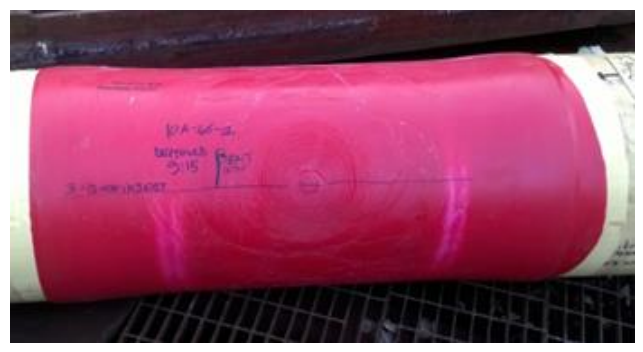

b)
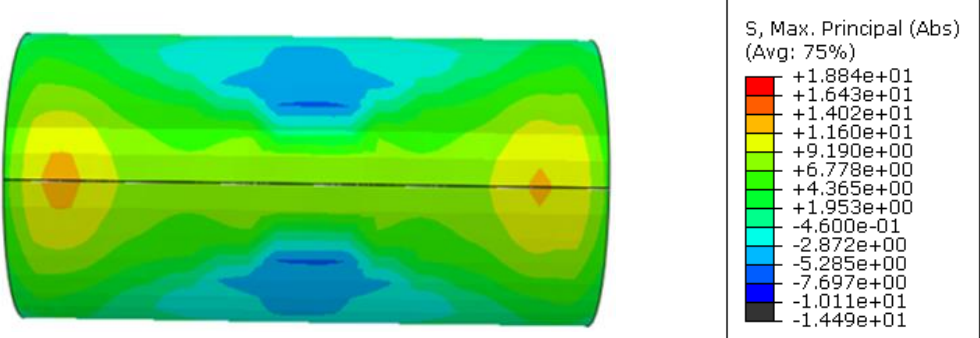

Figure 24: Pipe 4 - comparison of a) stress whitening observed during test with b) numerical prediction of stress. 
a)

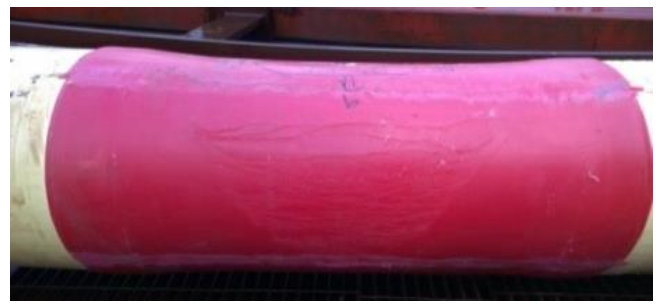

b)

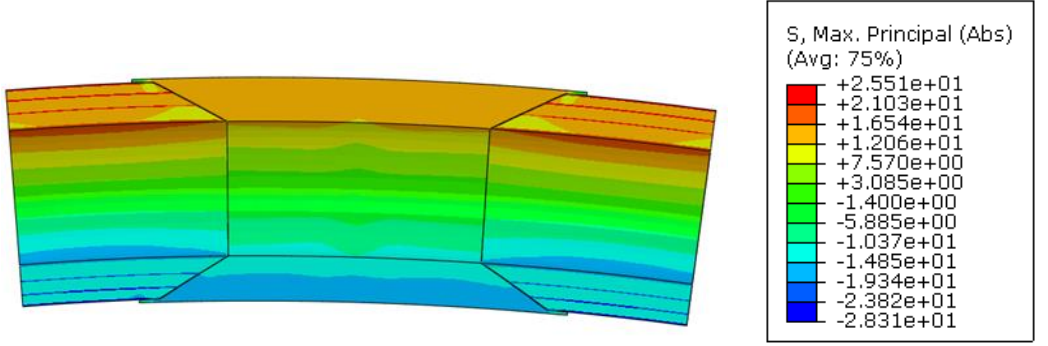

Figure 25: Full hourglass FJC bent after being fully cooled down; comparison of a) stress whitening observed during test with $\mathrm{b}$ ) numerical prediction of stress. 


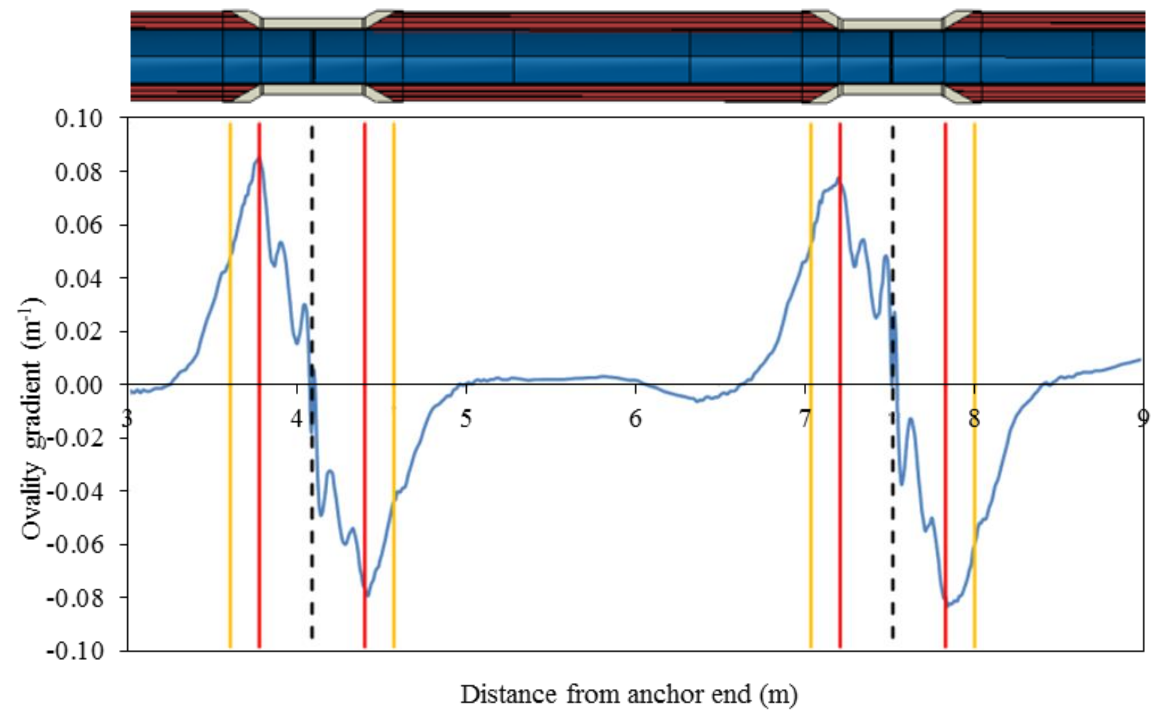

Figure 26: Ovality gradient along the length of Pipe 3 with chamfer locations overlain. 
a)

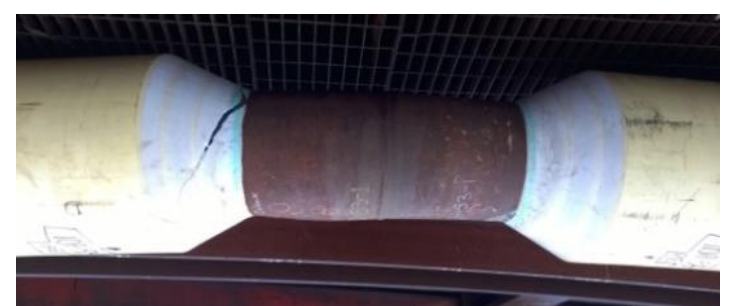

b)
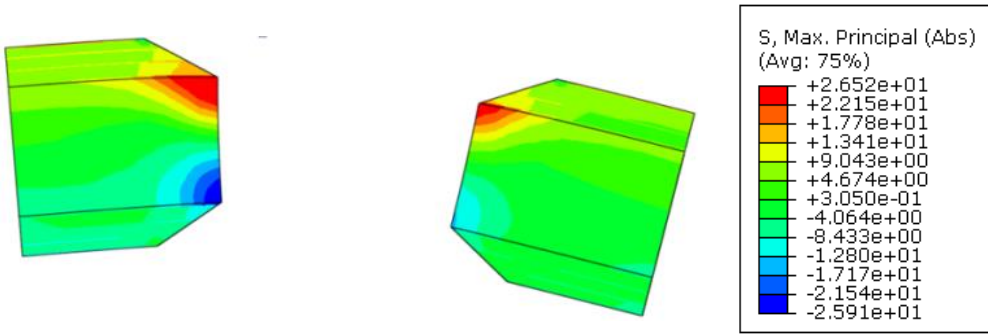

Figure 27: a) Cracking observable in the MLPP linepipe coating; b) numerical prediction of stress concentrations in the MLPP coating. 
Table 1: Typical ranges of thermal properties of pipeline materials.

\begin{tabular}{lcc}
\hline & $\begin{array}{c}\text { Thermal conductivity } \\
\left(\mathrm{W} / \mathrm{m}^{2} / \mathrm{K}\right)\end{array}$ & $\begin{array}{c}\text { Specific heat capacity } \\
(\mathrm{J} / \mathrm{kg} / \mathrm{K})\end{array}$ \\
\hline Steel & 44.5 & 475 \\
Solid polypropylene & $0.20-0.23$ & $1800-2500$ \\
Polypropylene foam & $0.17-0.19$ & $1500-2500$ \\
\hline
\end{tabular}


Table 2: Pipe bend tests simulated.

\begin{tabular}{ccc}
\hline Specimen & $\begin{array}{c}\text { Field joint coating } \\
\text { (nominal thickness) }\end{array}$ & $\begin{array}{c}\text { Cooldown time prior to } \\
\text { bending }\end{array}$ \\
\hline 1 & None & - \\
2 & Thin $(40 \mathrm{~mm})$ & $1-3$ hours \\
3 & Thick $(50 \mathrm{~mm})$ & $1-3$ hours \\
4 & Full $(100 \mathrm{~mm})$ & $1-3$ hours \\
5 & Full $(100 \mathrm{~mm})$ & $>24$ hours \\
\hline
\end{tabular}


Table 3: Connector displacements defined in order to simulate translation of pullhead during bend tests.

\begin{tabular}{lcc}
\hline Step & $\begin{array}{c}\text { Displacement w.r.t. } \\
\text { reel former }(\mathrm{m})\end{array}$ & $\begin{array}{c}\text { Displacement w.r.t. } \\
\text { straightening former }(\mathrm{m})\end{array}$ \\
\hline Bend to reel & 10.1 & 0 \\
Release & 7.5 & 0 \\
Straighten & 0 & 2.19 \\
Release & 0 & 0 \\
\hline
\end{tabular}


Table 4: Reduction in yield strength of X65 steel with increasing temperature.

\begin{tabular}{cc}
\hline Temperature $\left({ }^{\circ} \mathrm{C}\right)$ & $f_{\mathrm{y}}\left(\mathrm{N} / \mathrm{mm}^{2}\right)$ \\
\hline 0 & 526 \\
20 & 521 \\
50 & 501 \\
80 & 491 \\
110 & 486 \\
140 & 476 \\
\hline
\end{tabular}

